Cómo citar este trabajo: Gómez Mendoza, J. (2018). Cincuenta años de la Geografía Regional de España, obra universitaria, de escuela y de época (1968-2018). Boletín de la Asociación de Geógrafos Españoles, 79, 2744, 1-38. http://dx.doi.org/10.21138/bage.2744

\title{
Cincuenta años de la Geografía Regional de España, obra universitaria, de escuela y de época (1968-2018)
}

Fifty years of Regional Geography in Spain:

a University Spanish school and epoch-defining textbook

\author{
Josefina Gómez Mendoza \\ josefina.gomez@uam.es \\ Catedrática emérita \\ Universidad Autónoma de Madrid (España)
}

\begin{abstract}
Resumen
El texto conmemora los cincuenta años de la primera Geografía regional de España, concebida como una obra de la escuela geográfica española para ser un libro de texto para estudiantes universitarios, y libro de consulta para otros científicos afines y lectores cultos. La obra está dirigida por los dos grandes maestros de la geografía del siglo XX, Lluis Solé Sabarís, catedrático catalán de geografía física y Manuel de Terán, geógrafo humano de Madrid y en ella participan autores de distintas universidades españolas. Se estudia cómo fue posible el libro, la adopción que hace del método regional de la escuela francesa de geografía, entonces dominante, sus aciertos y limitaciones, así como la opción que hace importante que optara por la división en regiones históricas, solo levemente corregidas. También se considera en qué medida la obra traduce los grandes cambios demográficos y territoriales que se produjeron en la segunda mitad del siglo XX. Se concluye que, por ser un libro de texto universitario, resultado del trabajo conjunto de geógrafos de las diversas partes de España, y perteneciente a un momento de transformación del país, es uno de los libros que han hecho época en la geografía española.
\end{abstract}

Palabras clave: Geografía Regional; Regiones históricas; España; Solé-Sabarís; Terán; Cataluña. 


\begin{abstract}
The text commemorates the fifty years of the first Regional Geography of Spain, conceived as a work of the Spanish geographical school as a textbook for university students, and a reference book for other related scientists and educated readers. The work was directed by the two great teachers of 20th-century geography, Lluis Solé Sabarís, Catalan professor of physical geography, and Manuel de Terán, a human geographer from Madrid, and was written by authors from different Spanish universities. The history of the book is made, and the following of the regional method of the French school of geography, then dominant, is discussed. The option for the division into historical regions as true geographical regions instead of natural ones is considered. It is also analyzed to what extent the work translates the great demographic and territorial changes that took place in the second half of the 20th century. It is concluded that because it is a university textbook, result of the joint work of geographers of the different parts of Spain, and belonging to a moment of transformation of the country, it is one of the books that defined an era in Spanish Geography.
\end{abstract}

Key words: Regional Geography; Spanish historic regions; Spain; Solé-Sabarís; Terán; Catalonia.

\title{
1 Introducción
}

En 1968 se publicaba por la Ediciones Ariel de Barcelona, la Geografía Regional de España dirigida por Manuel de Terán (1904-1984) y Lluís Solè Sabarís (1908-1985), con la colaboración de varios profesores de geografía de las universidades españolas. Aunque se reconocía que debía haber salido primero una Geografía General de España, se justificaba la anticipación de la regional por cuestiones de necesidad. De hecho la general se retrasó diez años, y solo vio la luz en 1978, con los mismos directores y parte de los autores, junto con algunos más, todos profesores universitarios de geografía. El fin que perseguía la Geografía Regional de España (GRE, a partir de ahora) era claro desde las primeras líneas de la introducción: que los universitarios pudieran disponer de un manual superior adaptado a las exigencias pedagógicas y al nivel propio de un curso de geografía de España, que fuera a la par un texto moderno y escrito en su totalidad por geógrafos españoles pertenecientes a distintas universidades y regiones. Un libro, se dice también en las páginas introductorias, documentado y puesto al día, al nivel del público culto en general, e indispensable a multitud de especialistas de otras disciplinas. Eran unos años de cambio, los últimos de la dictadura, en ese tardo-franquismo, en que el país se estaba transformando económica, social e culturalmente, años de movilización universitaria y social, después del mayo 68 francés, que dio lugar en marzo 1969 en España a la declaración del estado de excepción y al cierre de universidades.

Lo que hace a este libro excepcional es que se presenta como una obra de escuela, la de los geógrafos de segunda generación del siglo (la primera fue la de Juan Dantín Cereceda, Pau Vila, 
etc.), nuevos catedráticos de geografía de las facultades de Filosofía y Letras de las distintas universidades españolas, reunidos bajo el liderazgo de Solé y de Terán, pese a sus diferencias internas, y en torno a un programa común de investigación geográfica que, en palabras de los directores, consistía en ir, a través de monografías regionales, corriendo "el velo extendido sobre las terrae incognitae hispánicas e ibéricas" (GRE, p. 4). Porque añadían, en efecto, "los geógrafos extranjeros frecuentemente [han calificado] a la Península de 'terrae incognitae'" (GRE, p. 3), esto es, de tierra geográficamente tan desconocida como antaño lo fueron los países de ultramar. Se aspiraba, por tanto, a hacer una síntesis geográfica moderna que completara o superara a las que se habían hecho desde ramas afines (geología, historia, meteorología, botánica, cartografía, etc.) y, sobre todo reemplazara a las geografías de España escritas por estudiosos extranjeros, en particular franceses y alemanes, verdaderos hispanistas o iberistas, para quienes el estudio de la Península Ibérica, o de alguna de las Españas y de Portugal, suponía gran rédito académico en sus países. Esta voluntad de superación (casi de restitución) la habían expresado ya antes de la guerra civil algunos de los autores en una "hoja volandera" incluida en uno de los volúmenes de la Geografía Universal de Vidal de la Blache y Lucien Gallois que estaba publicando la editorial Montaner y Simón: se decía en ella que se iban a ampliar los volúmenes de los países hispanoamericanos, labor que debía terminar con los tomos de España y Portugal, "que tenían que constituir el digno coronamiento de nuestros propósitos editoriales de nacionalizar la mejor y la más completa Geografía universal del mundo" [cursiva mía]. Firma estas palabras la editorial pero es una verdadera declaración de intenciones que se iría realizando tras la guerra, en concreto a partir de 1952, con la publicación del primer tomo de la Geografía de España y Portugal (GEP a partir de ahora) de dicha editorial Montaner y Simón.

En este texto me propongo estudiar la génesis y el significado de la GRE como hito en la serie de geografías de España, generales y regionales, de Cataluña y de otras regiones, que se fueron publicando entre los años cincuenta y los setenta. Expondré después el papel desempeñado por Solé y por Terán, los criterios de regionalización retenidos, entendiéndolos en su momento y en su contexto, así como el carácter de escuela que tiene el libro con la fijación de un protocolo de estudio regional, con los apartados de geografía general regional, y de geografía subregional o comarcal, y unos determinadas formas de escritura y de representación, así como unos razonamientos que se pueden calificar de posibilismo geográfico. Terminaré con la valoración que en el libro se percibe de los cambios que se advertían en aquellos años centrales del siglo, cuando se estaba en pleno proceso de los grandes movimientos migratorios interregionales, de industrialización y urbanización, lo que determinaría en seguida la agudización de los desequilibrios territoriales. 


\section{El lugar de la Geografía Regional de España (1968) en la serie de Geografías de España}

Se conoce bien hoy cómo se produjo la introducción de la geografía moderna en España y el papel que en ella tuvieron los naturalistas del laboratorio del Museo de Ciencias Naturales y de las cátedras de geografía física de las Facultades de Ciencia; del Museo Pedagógico Nacional y los profesores de las escuelas normales; de la Junta para Ampliación de Estudios e Investigaciones Científicas (JAE) a través de algunos pensionados, la Societat Catalana de Geografia (SCG) creada por Pau Vila y las relaciones de este con la Instituto de Geografía Alpina de Raoul Blanchard (Casassas, 1981; Gómez Mendoza, 1997, 2007, 2010, 2018; Ortega, 2003, 2006). Lo que ahora nos importa es la publicación por parte de grandes editoriales catalanas de libros de geografía general, universal, la que se llamaba descriptiva, es decir de geografía de los países. Retendré aquí algunos nombres y tres colecciones como antecedentes de la serie de geografías de posguerra.

\subsection{La Geografía de España de Martín Echeverría en Labor y la Universal de Gallach}

Leonardo Martín Echeverría (1894-1958), profesor de enseñanza media, y colaborador del Centro de Estudios Históricos (CEH), y geográficamente cercano a la antropogeografía de Ratzel, fue el encargado por la editorial Labor, que había iniciado sus actividades en 1923, de seleccionar los textos geográficos que debían incorporarse a su gran proyecto de publicación de manuales de carácter científico. En total se publicaron 30 textos de geografía, casi todos de autores alemanes, la mayor parte geografías de países o de conjuntos de ellos, el resto de geografía general. Entre los primeros estaban los tres volúmenes de Geografía de España del propio Martín Echeverría, el primero de geografía general de impronta ratzeliana, y los dos restantes de geografía regional. La obra, muy manejada por los profesores de geografía, fue objeto de tres ediciones entre 1928 y 1937; después de la guerra, Martín Echeverría partió al exilio, el libro fue dado de baja en el catálogo de la editorial (censurada en función de su autor, no por su contenido, que era bastante neutro) ${ }^{1}$ (Quirós, 1997, pp. 67-88 \& 75-76). En la parte regional, el esquema era básicamente de regiones históricas, con una gran región levantina que incluía a Albacete y Murcia, una región cantábrica (Asturias-Santander) y otra que englobaba Navarra-la Rioja.

Por su parte, y siempre en Barcelona, con un mayor mercado de libros y mayor demanda de saberes históricos y geográficos, el Instituto Gallach publicó entre 1928 y 1931, una Geografía Universal bajo la dirección del historiador Fernando Valls Taberner. Se quería presentar, de forma atractiva pero con base rigurosamente científica, "la descripción moderna del mundo", estudiada

1 También fueron dados de baja los libros traducidos por el autor. En 1940, desde México, Martín Echeverría publicó España. El país y sus habitantes con materiales que tenía antes de salir del país. En la Geografía se utilizan por primera vez bloques diagrama para la presentación del relieve. 
en el sentido de la perpetua transformación que estaban experimentando los hechos físicos y humanos. La obra de cinco tomos, es, en su mayor parte, una obra original de autores españoles e hispanoamericanos, entre ellos y por primera vez, Manuel de Terán, quien recién leída su tesis de historia del arte, era profesor del Instituto Escuela de segunda enseñanza de Madrid, colaboraba en el CEH institucionista, y en la cátedra de Geografía Política y Descriptiva que ocupaba Eloy Bullón en la Universidad de Madrid. Su capítulo, en el tercer tomo dedicado a España y Portugal, es sobre Castilla la Nueva: es su primer texto geográfico, y en él trata de encontrar trabazón entre los factores naturales y los hechos de geografía humana, de acuerdo con la definición aceptada de la geografía como estudio del hombre en relación con la tierra, del "medio geográfico". (Marías, 2007, pp. 188-189).

\subsection{La edición española de la Geografia Universal de La Blache y Gallois}

Por su parte la editorial Montaner y Simón emprendía por los mismos años la traducción y publicación al castellano de los libros de la Geografía Universal de Lablache [sic] y Gallois (GU) casi de forma simultánea a su aparición en Francia. Los geógrafos franceses han estudiado con detenimiento el proyecto, el desarrollo de la obra, interrumpido por las guerras mundiales, y cómo repercutieron en ella las circunstancias personales de Abert Demangeon. Como bien resume Lluís Ruidor acabó siendo es "una sucesión de monografías regionales sobre todos los países del mundo sobre el modelo propuesto por Vidal de la Blache en su Tableau de Géographie de la France". Lo importante es que la obra se empieza a publicar en España ya en 1928; hasta el final de la guerra se habían publicados 19 tomos, el primero de ellos, el muy celebrado de Demangeon sobre las Islas Británicas, traducido por Pau Vila, lo que no deja de ser un símbolo. La dirección de la edición española correspondía a los geógrafos y naturalistas más reconocidos del momento, Odón de Buen, de la Universidad de Madrid, Eduardo Hernández-Pachecho del Museo de Ciencias Naturales, Pau Vila ${ }^{2}$ que figura como profesor de geografía y ex alumno del Institut de Géographie alpine de Grenoble, y Emilio Huguet de Villar, del Instituto de Investigaciones y Experiencias Agrícolas y Forestales, junto con representantes hispano-americanos. ${ }^{3}$ Pero, más interesante aún: entre los colaboradores y traductores están los grandes nombres de los geógrafos del momento pertenecientes a la primera generación del siglo XX Juan Dantín Cereceda, Joan Carandell y Gonzalo de Reparaz (padre), los catedráticos de Instituto Salustio Alvarado, Rafael Ballester, Bartomeu Darder Pericàs, Rodolfo Llopis, entonces profesor de la Escuela Normal, junto con otras figuras como el arabista Pelayo Vizuete, dos o tres representantes de sociedades

2 Pau Vila publicó también entre 1929 y 1935 un resumen de la geografía de Catalunya con la editorial Barcino de 9 tomos.

3 Rosa Filatti, de las universidades de París y México y Fernando Ortiz de la Sociedad Geografica de Cuba. También pertenecían a la dirección de la edición española Vicente Vera por parte de la Real Sociedad Geográfica. 
americanas, y un profesor de geografía militar, Luis Villanueva López. ${ }^{4}$ A diferencia de las Geografías de Malte-Brun y de Élisée Reclus que habían tenido mucho éxito en España, esta nueva geografía universal era una obra colectiva con la intención de dar una visión moderna del mundo y de sus conjuntos regionales, con mayor atención a los grandes países, así como el propósito claro de difundir el método regional de la geografía francesa: relieve, clima, suelos y ríos, y en relación con ellos población, poblamiento, economía, ciudades.

Lo que verdaderamente nos importa ahora de la obra como antecedente y perspectiva sin la que la GRE no podría entenderse, es la voluntad inicial de "nacionalizar" e "hispanizar" la geografía en todos los tomos referidos a la Península Ibérica y los países ibérico-americanos. Como he dicho ya, en una hoja "volandera", al menos presente en los libros de 1930, con el título de "A nuestros lectores", se expresa la intención de ampliar la obra en los casos dichos, lo que ya se había hecho en el volumen dedicado a América del Sur. Guayanas. Brasil, en el que Emilio H. de Villar había introducido un extenso capítulo sobre "El desarrollo de la población en el continente americano desde el punto de vista ecético. ${ }^{5}$ Los siguientes tomos americanos, los tres de la edición francesa dedicados a las naciones entre México y la Tierra de Fuego, se habían convertido en cinco en la edición española, por ampliación de datos y fotografías, pero también por las "intercalaciones" sobre los más diversos temas realizados por Rosa Filatti, discípula en la Sorbona de de Martonne y Demangeon, y que había sometido estas ampliaciones al autor, que no era otro que Max Sorre. ${ }^{6}$ En esa mismo comunicado de la editorial Montaner de 1930, se advierte ya rotundamente que la geografía de España y de Portugal, que en francés había sido escrita en un solo volumen, iba a ampliarse a dos, y constituiría "el digno coronamiento de nuestro propósito editorial de 'nacionalizar' la mejor y más completa Geografía Universal publicada en el mundo."

4 En Ruidor (1987) se encuentra un estudio completo de cómo se hizo la edición española, su ritmo, sus traductores y su influencia. Hubo algunos años de interrupción por la guerra y eso supone que la edición en español de la Geografía Universal haya sido realmente una labor de dos generaciones. Es interesante constatar en la Tabla que se incluye que Pau Vila tradujo dos tomos, entre ellos el de las Islas Británicas, Carandell el también célebre de de Martonne sobre Alemania y Solé Sabarís, ya en 1948, la parte de geografía fíșica de la esperada Geografía de Francia. Por su parte, Jaume Vicens Vives tradujo el mismo año dos tomos sobre África (Riudor, 1987, p. 616).

5 Para del Villar, la Ecética es la parte de la geografía que estudia la capacidad de las sociedades humanas para lograr el máximo de las potencialidades del medio, que se traduce en mayor población. El mal aprovechamiento de los recursos en España, debido a una inadecuada gestión agraria y a la cesión de los recursos minerales a las compañías extranjeras, sería en este sentido una de las causas del atraso de España.

6 Los nuevos capítulos originales introducidos por Filatti que además es la traductora, son: "Colonización españolaCivilizaciones indígenas", y "El esfuerzo actual de México." Además se amplían los de "México y la vida moderna", y "Rasgos generales" en el que se resume un capítulo de la autora sobre "el índice de aridez" siguiendo el método del propio de Martonne, así como una nota sobre la bahía de Fonseca en relación con la injerencia de EE. UU. en los territorios centrales americanos. Se anuncia también que la ampliación para Cuba permitirá lograr la primera "geografía científica completa", que el autor de los estados de la Plata y Chile ha aceptado ampliar sensiblemente su obra y que la casa editorial ha enviado a América una misión para obtener materiales estadísticos y fotográficos para la edición en castellano (Montaner y Simón, 1930, Hoja). A propósito del libro de Sorre sobre las Islas Británicas, sí puedo referirme a un suceso personal, mencionaré que cuando yo empecé mi primer año de docencia, en 1969, precisamente de geografía de la Islas Británicas en la licenciatura de Filología Inglesa de la Universidad de Madrid, Terán me aconsejó el libro de Sorre (¡de 1928!) como bibliografía que seguía siendo fundamental. 
Era también Sorre, autor de un excelente estudio de los Pirineos atlánticos, quien había escrito en 1934 el tomo de Espagne et Portugal. El original se había traducido en 1936, pero, paradójicamente, no por un especialista, y desde el principio se consideró que no era suficiente. El equipo encargado de la obra quedó, por otra parte, desmembrado en la guerra civil, en función de los exilios (Vila, Reparaz, Santaló, Martín Echevería) o de los expedientes de depuración, y cuando se reemprende el proyecto se le encarga a Solé, catedrático de Geografía Física y Geografía Aplicada de Granada en 1940, y de Barcelona desde 1943, emprender una obra nueva hecha por verdaderos geógrafos conocedores directos del terreno, yendo a las fuentes originales y capaces de un obra de investigación. y no solo de recopilación y divulgación.

\subsection{La Geografía de España y Portugal de Montaner y Simón}

La Geografía de España y de Portugal (a partir de ahora GEP) en que figura Manuel de Terán como director fue mucho más que un coronamiento de la geografía española. Fue una obra nueva, eso sí, sobre el modelo francés. Empezó en 1952 con un primer tomo de Geografía física de España. El relieve, escrito por Solé, seguido dos años después, en 1954, por otro tomo sobre El clima. Las aguas de Valentín Masachs Alavedra, catedrático de Instituto y colaborador del Instituto Lucas Mallada de Investigaciones Geológicas del CSIC junto con La vegetación de Pío Font i Quer, del Instituto Botánico de Barcelona. Nunca se publicó el volumen de Geografía Humana, que hubiera sido el tomo III y que correspondía al director Terán, pero sí tres otros volúmenes de Geografía Regional (IV, 1-3) y uno de Geografía de Portugal, el tomo IV.1 (1958) comprendía Galicia, la región astur-cántabra, País Vasco, Mesetas Septentrional y Meridional, y Extremadura, todo escrito por Terán; ${ }^{7}$ el IV.2 (1966) incluye el Valle del Ebro, cuyo autor es José Manuel Casas Torres, Cataluña de Llobet, del Instituto Juan Sebastián Elcano de Barcelona (a partir de ahora el Elcano), y la Región Valenciana, de Antonio López Gómez. Finalmente, se publicaba en 1967, el volumen IV.3 que contenía Murcia, por Joan Vilà Valentí, catedrático de geografía de Barcelona, Andalucía por Jean Sermet, de la Universidad de Toulouse y gran hispanista, islas Baleares por Pierre Deffontaines, ex director del Instituto francés de Barcelona, e islas Canarias, que corrió a cargo, nuevamente, de Terán. El volumen de Portugal es el $\vee$, está redactado enteramente por Orlando Ribeiro y sigue el esquema habitual de formas de relieve, clima, aguas y vegetación, y geografía humana concluyéndose en la parte regional: "Así, la diferenciación del territorio portugués se asienta en hechos de geografía humana, puesto que las influencias naturales que en él se entrelazan le niegan unidad e individualidad" (Ribeiro, 1955, p. 12). ${ }^{8}$

7 Tan solo hay un capítulo II sobre "Paisajes y comarcas gallegas", cuyo autor es Ramón Otero Pedrayo (tomo, IV.1, pp. 46-91).

8 Para salvar la unidad del GU francesa se numeró a los tomos de geografía física como X.1, y posteriormente se aprovechó la parte de Sorre a la que se añadió la geografía de Portugal de Orlando Ribeiro como tomo X.2 
La obra se convertía, pues, en colectiva, (aunque no de "escuela" como iba a ser GRE), con una amplia participación de Terán y Solé, pero habiendo recurrido pese a todo a geógrafos franceses (Deffontaines, Sermet), y, sin duda, atribuciones de última hora como es el caso de Canarias a Terán. En ninguno momento se explica por qué no hubo (ni hay) geografía humana. Aventuraré alguna respuesta en seguida, a partir de la correspondencia entre Solé y Terán. Pero antes voy a terminar con la serie de geografías previas a GRE.

\subsection{Manuales de autores extranjeros o de iniciativa editorial extranjera}

El país estaba cambiando, sin duda, y una de las manifestaciones era el aumento enorme de estudiantes universitarios, particularmente notable en el caso de los estudiantes de Letras (García Ramón \& Nogué, 1992, p. 63) lo que condujo a que las cátedras y las asignaturas de geografía empezaran a crecer y apareciera, en consecuencia, un mercado universitario de libros de texto. "Las décadas de 1960 y 1970 se configuran [...] como un periodo decisivo para la consolidación de la comunidad universitaria de geógrafos" (García Ramón \& Nogué, 1992, p. 63) ${ }^{9}$. En efecto desde, mediados de los sesenta, con la aparición del llamado "problema universitario" (la contestación universitaria era un problema para el Régimen de Franco), se fue gestando una reforma universitaria que tiene uno de sus principales hitos en la creación de tres nuevas universidades públicas, las primeras desde 1917, Universidades Autónomas de Barcelona, Madrid y el País Vasco (Sáez Pombo \& Gómez Mendoza, 2018) y que culminó con la nueva Ley de Educación de 1970 y la elaboración de nuevos planes de estudio que supusieron la aparición de una especialidad de Geografía en segundo ciclo, con la consiguiente licenciatura y la división de la enseñanza geográfica en tres áreas y sus correspondientes profesores: Geografía Física, Geografía Humana y Análisis Geográfico Regional (López Ontiveros, 1992, pp. 5-7).

En cuanto a los libros de geografía de España, las Regiones naturales de España de Juan Dantín Cereceda de 1922, se habían reeditado por el CSIC en 1942 pero no pasó de ser un libro, consultado por los geógrafos y otros especialistas, pero poco leído por los estudiantes (Ortega, 1997). En él la delimitación de las regiones era de orden fisiográfico e hidrológico (montañas y depresiones, cuencas fluviales) y no podía servir para ninguna docencia de geografía regional y humana. En 1958, aparecía la Geografía de Catalunya, nuevamente con Solé como director (Paúl, 2017). ${ }^{10}$ En los años sesenta, y con la nueva demanda, vieron la luz algunos libros de autores

dándose por concluida la obra. De modo que Portugal de Ribeiro es a la vez tomo X.2 de la Geografía Universal y tomo $\vee$ de la de España (Marías, 2007, p. 197; Riudor, 1988, p. 150).

9 La geografía estaba muy escasamente representada hasta los años sesenta del siglo pasado en los planes de estudio: solo una Geografía general en los cursos comunes, una Geografía de España y de los pueblos hispánicos, así como una Geografía descriptiva del mundo en el último curso.

10 El propio Solé ha narrado las circunstancias de esta obra: había sido encargada antes de la guerra por la Lliberia Catalonia, después Casa del Libro, relacionada con Ediciones Aedos, a un ingeniero y literato, César August Jordana, quien nunca se había ocupado de geografía. Cuando salieron los primeros fascículos, personas vinculadas 
extranjeros, sobre todo franceses y alemanes: primero en 1964, el breve libro para las Presses Universitaires de France del hispanista Michel Drain, que prescindía, para la presentación, tanto de criterios naturales como históricos y presentaba una España interior más desarrollada frente a unas fachadas marítimas con mayor delimitación de unidades. Por encargo de la colección francesa, Magellan, también de PUF, dirigida por Pierre George, Joan Vilà Valentí, escribió La Péninsule Ibérique (1968) que se tradujo el mismo año al español y que según él mismo dice, mostraba las novedades tanto de orden físico como socioeconómico.

Mención aparte merece la Geografía de España y Portugal de Hermann Lautensach, publicada por la editorial Vicens Vives, en la colección Ecumene que dirigía Vilá Valentí, revisada y asesorada por Solé Sabarís, y traducida por la hija de este, María Solé Sugranyes. Es de mucha entidad, resultado de cuarenta años trabajando en la península, y es muy notable porque para la delimitación regional aplica su método geográfico, el de la transformación progresiva del paisaje, lo que le lleva a prescindir de todo criterio histórico, y a distinguir entre las regiones de la lberia siempre húmeda y las mucho más numerosas regiones de la lberia de veranos secos, es decir una división de carácter climático-ambiental. Muy lejos por tanto de la regionalización de GRE, que vamos a estudiar, pero muy presente sin embargo, en las mentes de los redactores, a quienes para la definición de las escalas mayores, las subregionales y comarcales, les gusta recurrir a umbrales de demarcación climático-paisajística sobre todo. Luego veremos algunas manifestaciones de esta contradicción.

\section{Los dos directores, Lluís Solé Sabarís y Manuel de Terán, maestros diferentes y complementarios}

\subsection{La relación entre Solé y Terán}

A la muerte de Terán en 1984, Solé Sabarís, le dedicó un escrito de homenaje que tituló "paralelismo de Pau Vila y Manuel de Terán", donde evocaba a ambos como maestros de la geografía española. Es un texto que emociona porque Solé apenas sobrevivió un año más, pero también porque se comprueba que ese artificio de trayectorias paralelas a las que recurre el geólogo catalán está disimulando que el verdadero paralelismo es entre él mismo y Terán, maestros admirados y que lograron, por su calidad científica y personal, que la geografía se hiciera visible en el tablero de la universidad española e internacional. Rigurosos contemporáneos, compartieron bastantes hechos biográficos, por ejemplo, el haber sido ambos profesores de los Instituto Escuela,

a Pau Vila y a la geografía, protestaron por su escasa calidad, por lo que la obra se le encargó finalmente a Gonzalo de Reparaz, quien empezó a dirigirla pero tuvo que renunciar al irse al exilio tras la guerra. Transcurridos unos años la editorial reconstruyó el antiguo equipo de Pau Vila, dirigido ahora por Solé Sabarís, "en la que nos reunimos todos los disponibles, catalanes y franceses", otros jóvenes nuevos, y hasta el propio Pau Vila, a su vuelta a Cataluña en 1961. La obra de Aedos se publicó entre 1958 y 1974 (Solé, 1987, p. 93). 
Terán en el de Madrid, Solé en el del Parc de Barcelona - del que, por cierto lo fue asimismo Vicens Vices-; ambos fueron también pensionados por la JAE, uno para modernizar la geología del Mediterráneo que se hacía en España, el otro para aprender de Demangeon los métodos de geografía humana; sobre todo, los dos fueron grandes maestros modernizadores y sintetizadores de la geografía española de la segunda mitad del siglo XX en sus campos respectivos, y sus nombres han quedado unidos en las dos grandes geografías de España, la de Montaner de 1952-1967 y la de Ariel de 1968-1978. El nombre de Solé, está unido asimsmo a la de Catalunya, que también hay que celebrar a los sesenta años de su aparición (Paül, 2017) y a la morfología del relieve peninsular: el libro de Solé y Birot sobre la geomorfología de la Cordillera Central, que publicó el Elcano, es sin duda uno de los clásicos de la geografía del siglo XX (Birot \& Solé, 1954). Y Terán les acompañó en algunas de las campañas de reconocimiento que efectuaron.

Toda la documentación que se conserva y los escritos de ambos muestran lo cercanos que se sintieron. Probablemente esa gran amistad y confianza intelectual y científica se fraguó con motivo de la reunión de geografía celebrada en Jaca, en 1946, organizada por el Instituto de Estudios Pirenaicos, al que asistieron profesores de enseñanza media y universidad convocados por el Elcano, juntos con los portugueses con Orlando Ribeiro a la cabeza. Lo he contado en más de una ocasión con detenimiento: allí se produjeron encuentros y se fraguaron libros y programas de trabajo (hábitat rural y trashumancia) (Gómez Mendoza, 1997, pp. 129-130). No pudieron, claro, asistir los exiliados, tampoco los geógrafos franceses porque la frontera estaba cerrada, en aquel inútil gesto de Francia que parecía querer "compensar" que la victoria de los Aliados no hubiera supuesto la esperada caída del régimen de Franco.

Para ver cómo se fraguó la relación entre Solé y Terán sirvan las palabras del primero: "La simpatía y compenetración con Terán fueron inmediatas, acentuadas con la convivencia en Jaca y en una de las excursiones de dicho Congreso dirigida por Orlando Ribeiro, no en balde dada la afinidad de nuestros sentimientos ideológicos." (Solé, 1997, p. 93). O también "[N]uestra amistad se trabó pronto a través de la geografía hispana, aun desconociendo nuestras afinidades anteriores" (Solé, 1984, p. 192). Por eso, dice, cuando desde la editorial Montaner se la ofrece emprender la gran Geografía de España, proyectada inicialmente, como he contado, para Pau Vila y Max Sorre, puso como condición la codirección de Terán, "única persona que GRE entonces a mi modo de ver, podía llevarla a cabo". Así empezaron una colaboración y una "compenetración científica", de las que resultan al menos la GEP (1952-1967), la GER, pero también la transmisión de competencias mutuas, geomorfológicas por un lado, de geografía humana por el otro, y el compartir lo que el maestro catalán llama "los entusiasmos geográficos", además de muchas campañas de trabajo de campo como las de la Cordillera Central con Birot. 
La correspondencia entre ellos había empezado ya antes de Jaca, pero inmediatamente después se confirman los primeros proyectos: Solé (que era secretario de la delegación del CSIC en Barcelona - pese a su pasado catalanista-, a petición de José María Albareda, el todo poderoso secretario del mismo ${ }^{11}$ ) acepta también la responsabilidad de dirigir la sección del Elcano de Barcelona que le propone Terán y donde desempeñará su actividad Salvador Llobet, el geógrafo-discípulo por antonomasia de Solé. No deja de ser curioso que Solé se mencione a sí mismo al final de su vida como codirector de la Geografía de Montaner cuando en realidad solo figura Terán. Y es que realmente lo fue: tuvo el encargo editorial, la iniciativa de una doble geografía de España, la de Sorre, y la española, la decisión de nombrar a los colaboradores, no sin antes consultar escrupulosamente con Terán, y, sobre todo, en este caso como en el de la GRE, tuvo que encargarse de la "persecución" de los autores morosos para que entregaran sus contribuciones y no paralizaran la obra. Una coordinación y una solicitud en la que muestra una enorme delicadeza y una paciencia infinita según acredita su correspondencia. Resulta divertido y emocionante, que Solé, en el homenaje a Terán, no pueda evitar mencionar la dificultad que tuvo siempre para obtener los textos de este "con el desespero que es de suponer de sus editores." "Terán, dice, era más prolífico en el diálogo que en sus textos" (Solé, 1984, p. 193) "no debió ser hombre de fichas sistemáticas, pero sí un buen escritor español." 12 Y para muestra su pertenencia como miembro numerario de las Reales Academias Española y de la Historia. En cambio, la capacidad y la paciencia de Solé para compartir planes y proyectos, decidir colaboradores, resolver modificaciones, pedir lo retrasado, buscar soluciones alternativas, pacificar en los casos necesarios las relaciones entre autores y editoriales, son proverbiales. Parece que en los casos de la GEP y de la GRE esta insistencia la tuvo que ejercer en varias ocasiones con Llobet, Terán y Jesús García Fernández.

Cabe preguntarse algo a lo que solo se puede responder con hipótesis. Por qué Solé no recurrió, en su proyecto editorial, a José Manuel Casas Torres, miembro como Albareda del Opus Dei, que después de hacer una tesis sobre la huerta de Valencia, se había convertido en joven catedrático de Geografía de la Universidad de Zaragoza, persona eficaz y que tenía a su disposición en términos relativos muchos más medios, muchos para la época. Ambos colaboraron estrechamente como director y secretario- en el Instituto de Estudios Pirenaicos de Jaca, al que Albareda concedía una enorme importancia: quería convertir al Pirineo en un "laboratorio" de estudios científicos transdisciplinares en sustitución, decía él, del Guadarrama, a su juicio ideologizado por los

11 Lo fue hasta finales de los años cuarenta. Entonces hubo una denuncia de su pasado catalanista y tuvo que renunciar (Gómez Mendoza, 2018).

12 La frase completa de Solé no tiene desperdicio: "Se adivina en sus escritos [los de Terán] un cierto desorden material, hasta el punto de dar textos a veces impracticables para la imprenta, pero siempre con una corrección gramatical propia de un buen escritor español, quizás algo recargado para el gusto de un escritor catalán, siempre más lacónicos y menos barrocos." \{Solé, 1984, p. 95). 
institucionistas (Gómez Mendoza, 1997, pp. 120-122). Quizá, con Casas, las cosas hubieran sido más rápidas, pero sin duda sin la misma categoría. Leídas muchas páginas de correspondencia entre Solé y Casas y Solé y Terán, solo se me ocurre una explicación: Terán le inspiraba mucha más confianza intelectual y científica, se compenetraban más. Solé sabía de las amarguras pasadas por Terán después de la guerra, de su expediente de depuración, de que estuvo prudentemente automarginado, de que entró en el Elcano con discreción: "Pero después de los altibajos de los tiempos de máxima turbulencia en que flotaban tantas vilezas que permitían destacar a ambiciosos y mediocres, el papel de Terán se fue imponiendo lentamente por su valor. [...] Pudo llevar la revista más directamente, dictar cursos y conferencias y en 1951 se le abrieron las puertas de la universidad madrileña, desde la cual su proyección fue más fácil y fecunda." (Solé, 1997, p. 90). Cuando Terán obtuvo la cátedra tenía 47 años, Solé había ganado la plaza con 33 y Casas Torres con 28 .

Antes de concluir este apartado sobre las relaciones entre Solé y Terán, quiero añadir algo que dejó escrito el primero de forma breve en la "Evocación de Manuel de Terán, geógrafo, humanista y mentor (1904-1908)", sobre cómo veía Terán la "cuestión de Cataluña". Solé creía que su gran amigo conocía bien Cataluña y la cultura catalana, pero "sobre tot crec que nos ens comprendia prou." "En nuestras conversaciones (...) era eso un motivo de diferencia que yo evitaba, buscando la coincidencia en otros puntos, ya que no la podía alcanzar en este terreno." (Solé, 1984, p. 195). Le molestaba en concreto, y lo interpretaba como una desafección, que, en Estudios Geográficos no se hubiera escrito ni siquiera una reseña de la Geografía de Catalunya. Pero también creía que en la última época Terán había cambiado en el sentido de dar más razón a Cataluña, hecho que le agradaba como, también, le agradecía que hubiera hecho explícito el apoyo de la universidad de Madrid a las posiciones catalanas en el momento en que el Ministerio de Educación consideró la posibilidad de incluir, en los manuales, Lérida en el Valle del Ebro y separarla de Cataluña. Luego, lo explicaré.

\subsection{La colaboración en las GEP y en la GRE: un libro de escuela por encima de las corrientes}

A finales de los años cuarenta, el plan de trabajo de la GEP está establecido: la geografía física corría a cargo de Solé, Terán había mostrado interés en hacer toda la geografía general humana salvo unas páginas de geografía histórica de Amando Melón, el catedrático de geografía y director del Elcano. En una carta de 1948 aparece decidido el contenido: una geografía histórica de Melón (25 pp.) la geografía económica, que sería el cuerpo del libro, de 200 páginas, a cargo de Terán, y otras dos cortas contribuciones, una de Llobet sobre la población (aunque Solé dice que también le gustaría intervenir en la industria) y otra sobre la casa y el poblamiento de Casas Torres. Aparece el primer tomo, el del relieve de Solé en 1952, el segundo de clima y vegetación en 1954, y la 
geografía humana sigue sin llegar. Terán acababa de publicar un manual de geografía descriptiva del mundo, Imago mundi (1952), y esto, junto con sus artículos de investigación, la redacción de la revista, la elaboración de las partes regionales, y la doble docencia en el Instituto Beatriz Galindo y la Universidad quizá le impidieran acometerlo. O quizá la tarea era demasiado ardua y demasiado nueva.

El retraso afecta incluso la introducción a toda la obra, el prólogo que, como director, tenía que escribir para el inicio del libro I, el del relieve de Solé que ya estaba compuesto. Ese prólogo acabó llegando y quizá es uno de los textos más bellos y celebrados de la geografía española, en fondo y forma, uno de los más cercanos al Tableau de géographie de la France de Vidal de la Blache: "La genialidad geográfica de la Península Ibérica" (Terán, 1952, pp. 3-13), una península diversa y contrastada, tan capaz de comunicarse con el continente europeo como de cerrarse sobre sí mima, mediterránea y atlántica a la vez, en la que, por su estructura, muchas veces se ha impuesto la diversificación política, en la que el clima, la vegetación y la historia, han construido gran variedad de paisajes agrarios, "paisaje amasado de tierra y de cultura": "Pese a la diversidad regional de tipos y temperamentos, una caracterización general es posible para el conjunto de los pueblos peninsulares [...] Existe una genialidad ibérica cuyas raíces vienen de ese fondo originario y a cuya formación ha contribuido la aportación espiritual de los diversos pueblos y culturas para los que España ha sido crisol y fundente." (Terán, 1952, p. 13) (Gómez Mendoza, 2007). En carta a Solé (22.09.1949) Terán reconoce que no le había sido nada fácil escribir esa introducción, que había optado, al ser para la parte general, por "una síntesis a grandes rasgos, seleccionando los más expresivos, eliminando los datos concretos, y animándolo literariamente. [....] No sé lo que habrá salido, pero ha salido." Añade: "ahora a trabajar en lo demás, pues creo que a la geografía española le va mucho de su crédito en el que esta obra pueda adquirir" (Correspondencia, 22.2.1949). ${ }^{13}$ Fuera por este otro trabajo -todo el tomo IV.1 (Galicia, región astur-cántabra, País Vasco y la dos submesetas) - que se publicó en 1958, fuera por lo que fuere, la geografía general humana, lo vuelvo a decir, nunca vio la luz.

Ya a mediados de los años cincuenta Lluís Solé empieza a hablar del nuevo proyecto, el de la Geografía Regional de España y de mantener una reunión para decidir la estructura. Añade que se va a poner de acuerdo con Casas y que quizá en una entrevista "se podrían conciliar criterios, que a primera vista parecen muy opuestos en su forma, pero quizá menos en el fondo" (Correspondencia, 3.5.1954). Esa reunión se celebró con la presencia de los responsables de la editorial Ariel, y aunque no puedo precisar la fecha, en ella se comentaron o discutieron los

13 Para hacerse una idea de los plazos de la época y aunque pueda parecer increíble dos años después, Terán vuelve a mandar el prólogo y suplica que presten atención a las omisiones que ha cometido al final de ciudades de más de 100000 habitantes y que no ha podido corregir porque no le han mandado las pruebas de imprenta (9.2.1951). 
criterios de regionalización de España y se distribuyeron las partes entre profesores de geografía, de las distintas universidades. En la Presentación del GRE se dice, en efecto, que "un grupo nutrido de profesores de geografía en el que se hallan representadas la mayor parte de las tendencias y orientaciones, se ha propuesto proporcionar a sus discípulos y al público español un texto adecuado [a los cursos de geografía de España de universidades, escuelas técnicas, militares, etc.]" (Terán \& Solé, 1968, p. 5; subrayado mío).

En el homenaje rendido a Solé en 1979, Terán le calificaba de figura-puente de la geografía española (Terán, 1979, p. 259) , interlocutor y mediador entre esas "tendencias y orientaciones", dicho de forma más clara, al menos entre las dos diferentes familias o grupos, que se identificaron (y se separaron) durante muchos años por sus respectivos maestros "los de Casas [Torres]" y "los de Terán", pertenencias que, sin lugar a dudas, se traducían en los tribunales de oposición (de miembros sorteados) por las mayorías de unos o de otros (era frecuente oír "este es un tribunal de 3-2 o de 4-1"), también quizá por su entendimiento de la geografía y su forma de pensar, al menos eso se creía entonces. Se deduce de las palabras de la presentación que he transcrito que los autores son considerados los más oportunos para encargarse de las regiones respectivas, pero que también se cumple con un requisito no explícito de representación de "familias": es un éxito, sin duda, de Solé, de su autoridad, de su capacidad de diálogo; quería que el libro fuera un libro de escuela, y se puede decir que lo fue. "Los de Terán" en este libro son Jesús García Fernández y Antonio López Gómez, catedráticos respectivamente de Valladolid y de Valencia, encargados de la submeseta Norte y León y de la región valenciana; los de Casas, Salvador Mensua, catedrático de la universidad de Zaragoza, y en cierta medida, por sus orígenes zaragozanos, Joaquín Bosque Maurel, catedrático de Granada, que se encargaron, el primero, del Valle del Ebro (Aragón, Navarra y Alto Ebro) y el segundo de Andalucía. A Terán le correspondió Galicia, la región Cantábrica, el País Vasco, y además (en parte por falta de candidato) Canarias y plazas y provincias africanas, que había estado estudiando unos años antes. Solé no hizo el estudio de ninguna región, cedió Cataluña a Salvador Llobet, aunque lo siguió muy de cerca y en cambio se reserva la introducción sobre las regiones españolas. ${ }^{14}$ Finalmente colaboran también Joan Vilá Valentí, cercano a Solé, a quien le corresponde Murcia porque había ocupado la cátedra de esa universidad, aunque ya se había trasladado a Barcelona; y Bartolomé Barceló Pons, geógrafo balear, también cercano a Solé, y que pronto ocuparía la cátedra de Palma de Mallorca.

Todos los capítulos de las regiones están estructurados de la misma forma: una introducción de conjunto sobre la región (personalidad, factores o rasgos de conjunto, en suma caracterización); después una parte general (luego veremos en qué proporción) compuesta, según el método regional -medio físico, relieve, clima y vegetación, poblamiento y población, economía agraria,

14 Fue una cuestión para él prioritaria, volvió sobre ello en 1982-83 en un artículo metodológico. 
industrial y ciudades, en su caso, comercio- y luego una segunda parte de aspectos regionales, con estudios comarcales más o menos extendidos, y finalmente la bibliografía correspondiente.

\section{Una regionalización histórica de España, diez años antes de la Constitución}

\subsection{El abandono de la tradición geográfica de las regiones naturales}

No fue la regionalización de España de GRE una verdadera aportación de la obra que estoy comentando, aportación que radica ante todo en su misma existencia y en sus contenidos. Lejos de ahí: la opción fue pragmática, por regiones históricas con algunas leves modificaciones que ahora diré: los directores no se molestan en exceso en justificar esta regionalización, conscientes de que el valor del libro estaba en su desarrollo. "La Península se estudia a través de sus regiones históricotradicionales, [...] por cuanto la mayoría de ellas constituye el mejor reflejo del sustrato estructural peninsular [...] modificadas en aquellos casos en los que evidentemente no hay acuerdo con la realidad geográfica, como en el caso de la provincia de Albacete [que es más manchega que murciana], y asimismo de la provincia de Santander, incorporada por todos los geógrafos al conjunto regional cantábrico" (GRE, pp. 22-24) (Figura 2). Es decir, que en cierta forma se incurre en una definición tautológica pero razonable: a la escala subestatal, las regiones geográficas tenían que ser las configuradas históricamene. Como comentaré luego, en el desarrollo de algunos capítulos, se advierten diferencias de criterio con este principio general y, también, en comentarios posteriores, algunos de los autores dieron a entender que no estaban enteramente de acuerdo.

La gran novedad que marca época es que los profesores de geografía, en el inicio del último tercio de siglo, prescinden de las regiones naturales que habían prevalecido en toda primera la mitad de siglo XX, sobre todo con la obra de Juan Dantín Cereceda de 1922, reeditada después de la guerra, y de la Fisiografía del solar hispano de Eduardo Hernández-Pacheco; en los conjuntos regionales formados por agrupación de las regiones históricas, sí se pueden leer las grandes estructuras ibéricas -Macizo central ibérico o Meseta, cordilleras de borde, depresiones exteriores del Ebro y del Guadalquivir, Cordilleras alpinas Pirineos y Bética. ${ }^{15}$ Como ilustración de la inadecuación de la región natural para esta escala subestatal se presenta el caso de Aragón, que se admite como una de las regiones de personalidad más indiscutida y acusada, económica, histórica y socialmente, y que, sin embargo, está compuesta por tres grandes unidades fisiográficas, el Pirineo, la Depresión del Ebro y la Cordillera Ibérica. Del mismo modo, aun reconociéndole coherencia geográfica, se abandona toda tentación de seguir el criterio de división de Lautensach, que se basa en el clima y en el grado de transformación del paisaje, por lo que configura un mapa

15 Hay que llamar de nuevo la atención sobre esa lectura tan meseto-céntrica (a la postre castellano-céntrica) del mapa estructural: centro, borde, exteriores, periféricos. 
que va de la España húmeda a la seca y árida, con sus subdivisiones. Las regiones históricas se imponen para su estudio por los geógrafos españoles, en la medida en que traducen, en rasgos generales, la trabazón básica física y humana. Por razones de pragmatismo se aceptan además las delimitaciones provinciales, salvo en contados casos que no figuran en el mapa general. En realidad, la justificación de cada identidad regional se acaba haciendo, en el libro, más a posteriori que a priori, como introducción a cada capítulo, y el conocimiento geográfico del medio con fines de definición y delimitación se traslada a la escala siguiente, la de las unidades subregionales, es decir, las comarcas.

Figura 1. Portada de la obra Geografía Regional de España.

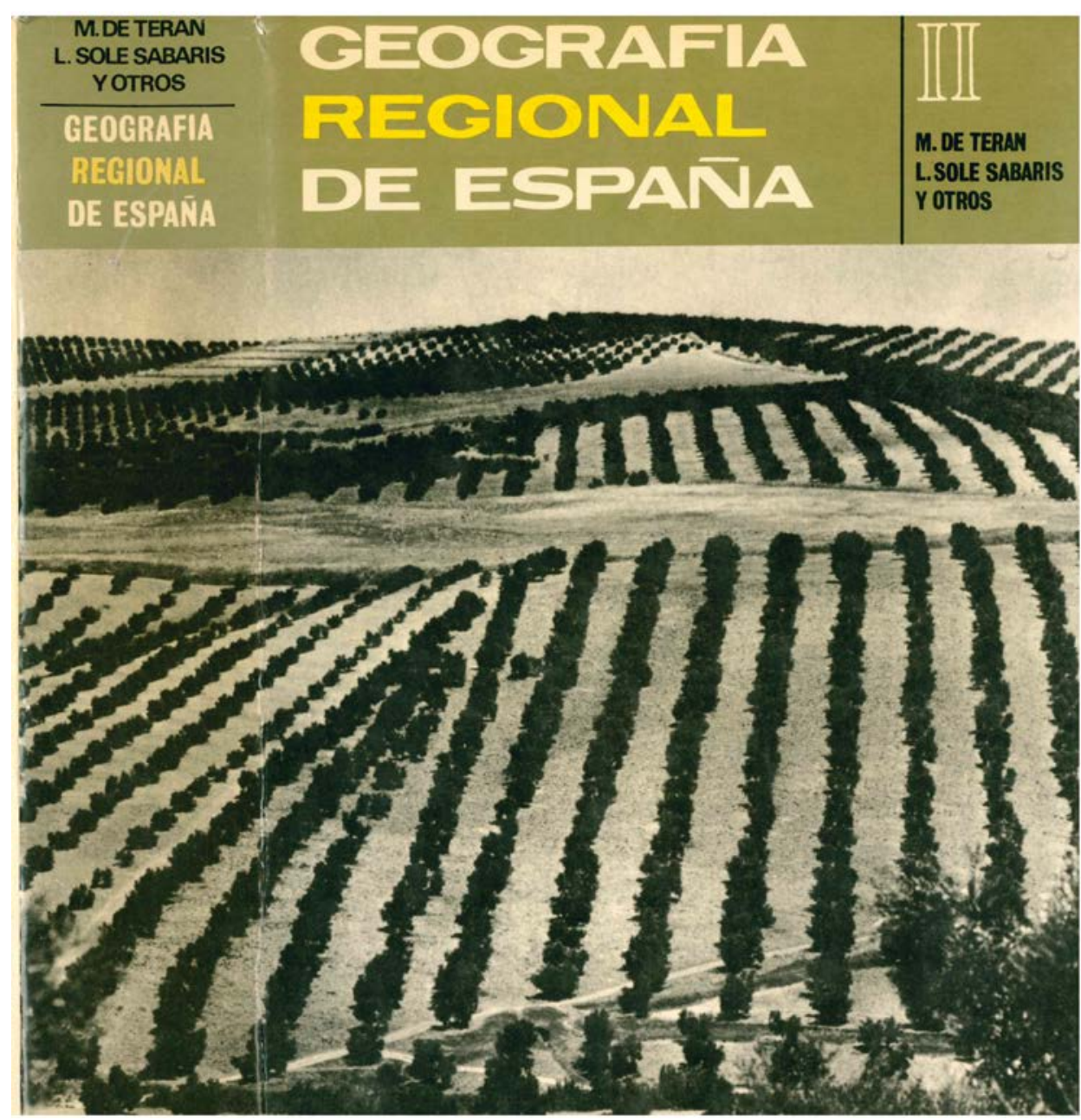

Fuente: GRE (1968). Editorial Ariel

\subsection{Regiones económicas y funcionales}

Hay que tener en cuenta que desde finales de los años cincuenta, pero sobre todo en los sesenta, el desarrollo económico se empieza a traducir en grandes transformaciones territoriales. El hecho ocupa entonces a especialistas de distinta procedencia, sobre todo economistas y demógrafos, científicos regionales, de los que se puede citar a Gonzalo Sáenz de Buruaga, Eduardo 
Barrrenechea, Ramón Tamames, Ramón Trías Fargas, Julio Alcaide Inchausti, Ramón Perpiñá Grau, etc; en todos, predomina la convicción de que, ante los procesos de integración económica y de la urbanización, se necesitan divisiones de regiones funcionales y polarizadas, basadas en los polos y nodos de desarrollo, es decir las ciudades, y que tengan en cuenta el nuevo mapa territorial de un país que se está urbanizando velozmente y en el que se han iniciado movimientos migratorios interregionales de cientos de miles, si no de millones de personas. De entonces son muchas propuestas de división regional de España, en algunas de las cuales se procedía incluso a hacer ajustes provinciales y comarcales.

Nunca he sabido por qué, de todas las propuestas de aquellos años, se recurre en la GRE a una propuesta de regiones nodales del Instituto Nacional de Industria de 1964 firmada por González Plaza y Prieto y que se reproduce en el libro: está basada en un trabajo del desarollista, José Isbert, y presenta la curiosidad de delimitar 16 "sectores de la región económica no coincidentes con los límites provinciales" (Figura 2). Solé Sabarís, comenta que cada vez más los geógrafos tendrán que contar con la economía y con los economistas para establecer la estructura regional, base importante para la organización social y administrativa de un país, aunque el hecho geográfico sea más complejo y tenga que tener también en cuenta también las implicaciones culturales y sociales.

Figura 2. Regiones económicas nodales de España

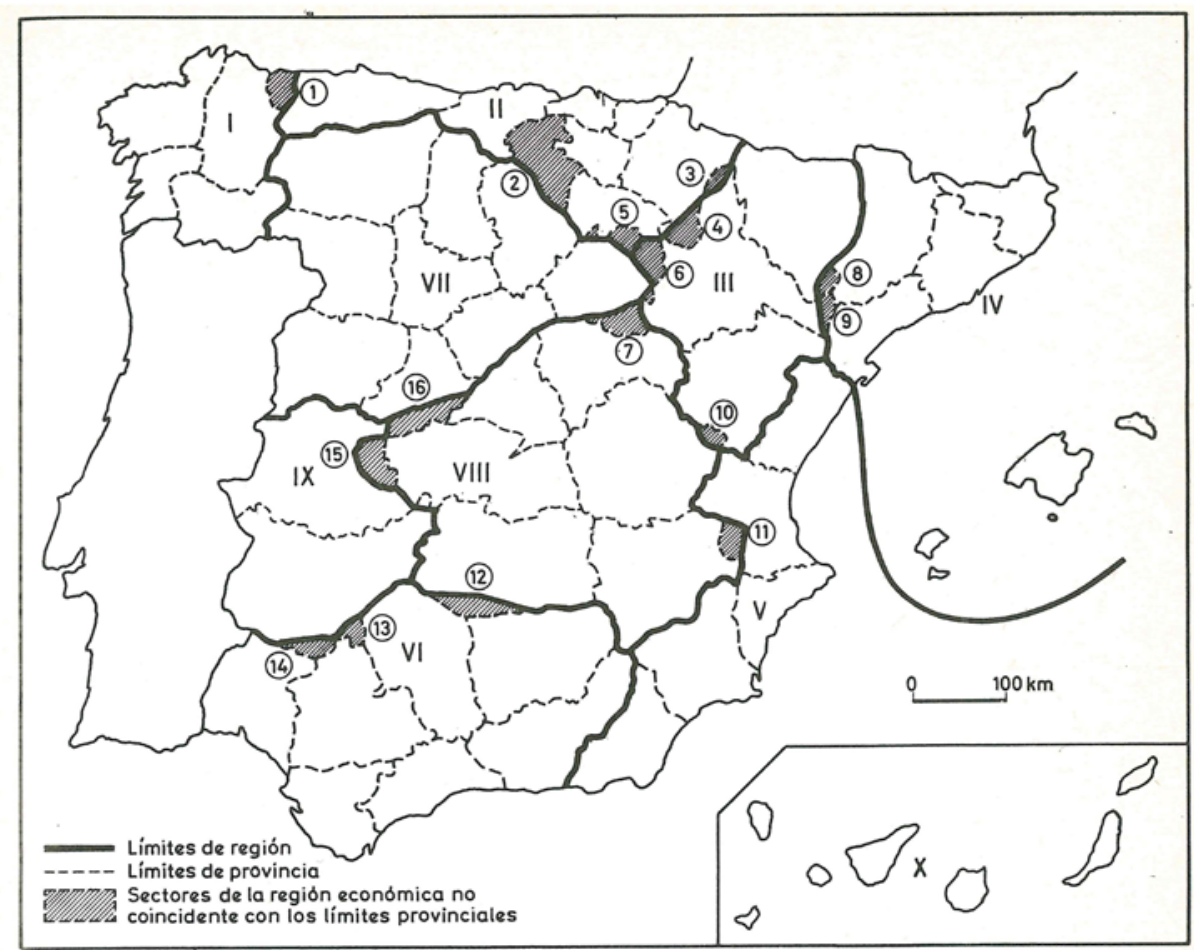

(1) Castropol (2)Villarcayo, Sedano, Miranda de Ebro, Briviesca, Belorado y (Condado de Treviño) (3)Sos del Rey Católico (4) Tudela (5)Zona de Sierra (6)Agreda (7)Medinaceli (8)Fraga (9)Zona de Mequinenza (10)Rincón de Ademuz (11)Ayora (12) Zona de Sierra Madrona (13)Zona de Azuaga (14)Zona de Monesterio (15)Navalmoral de la Mata (16)Arenas de S.Pedro y Cebreros FIG. 2. - Regiones económicas nodales de España, según el INI, por González Plaza y Prieto.

Fuente: GRE (1968, p. 23). Editorial Ariel 
Todos estos trabajos de ciencia regional de los años sesenta y setenta quedaron de algún modo ocultos o desdibujados por el principio de disposición autonómica reconocido en la Constitución de 1978 y la rapidez con que se fueron aprobando las Comunidades Autónomas. Pero no dejan de ser interesantes. Un suplemento del periódico Informaciones Económicas, que recogía a menudo estas ideas, planteó en su edición del sábado 31 de marzo de 1973, a los economistas citados y otros, la pregunta de si era necesaria la regionalización de España. Las respuestas son casi en todos los casos afirmativas y algunas premonitorias: por ejemplo, Ramón Trías Fargas, el economista en Barcelona del Banco Urquijo y de la editorial Labor, posterior político en Convergencia i Uniò, se alineaba con la posición de José Luis Sampedro de que las regiones económicas estaban viniendo a coincidir con las regiones históricas. "Cataluña, por ejemplo, definida en los términos que utiliza la economía regional moderna, coincide perfectamente con la Cataluña del Principado, que es la Cataluña industrial, histórica y lingüística. Lo mismo puede decirse de la mayor parte de las regiones tradicionales". Su opción ideal era la organización federal del Estado invocando el ejemplo de Alemania y Suiza. Otros optaban por divisiones más funcionales.

\subsection{El criterio ecléctico de regiones históricas, con algunas modificaciones. Los casos de Navarra y Lleida}

En suma, dice en la introducción Solé, "el criterio sustentado en la obra tenía que ser forzosamente un tanto ecléctico [...] Así, la Península se estudia a través de sus regiones históricas tradicionales, modificadas en aquellos casos en los que evidentemente no hay acuerdo con la realidad geográfica, como en el caso citado de la provincia de Albacete y asimismo de la de Santander incorporada por todos los geógrafos al conjunto regional cantábrico" (GRE, p. 21-22). De este modo, respecto a las regiones tradicionales, las novedades son que Santander se incorpora con Asturias a una "región Cantábrica", Logroño a un conjunto llamado Navarra-Alto Ebro, Albacete se segrega en su mayor parte de Murcia para integrarse en Castilla la Nueva (Figura 3). Lo más llamativo del libro quizá sea el caso de Aragón y Navarra: el capítulo 6, cuyo autor es Salvador Mensua de la Universidad de Zaragoza, se llama de hecho "el Valle del Ebro", y en el se integran también Navarra y la Rioja, lo que evidentemente es una decisión de carácter mayor: "el Valle del Ebro, dice el autor, se nos presenta como una gran unidad física plenamente individualizada en el conjunto de las tierras peninsulares. [...] Los primitivos reinos cristianos que, con origen en el Pirineo, extendieron su hegemonía a la depresión y al sistema lbérico, [formaron] unidades políticas de fuerte cohesión que tomaron como eje el valle del Ebro [y ahora] tienen dependencia económica y administrativa [de Zaragoza]. " (Mensua, en GRE, p. 194). En suma, Navarra en su totalidad queda separada enteramente del País Vasco, y estudiada con Aragón. 
FIG. 3.-Regiones geográficas de España.

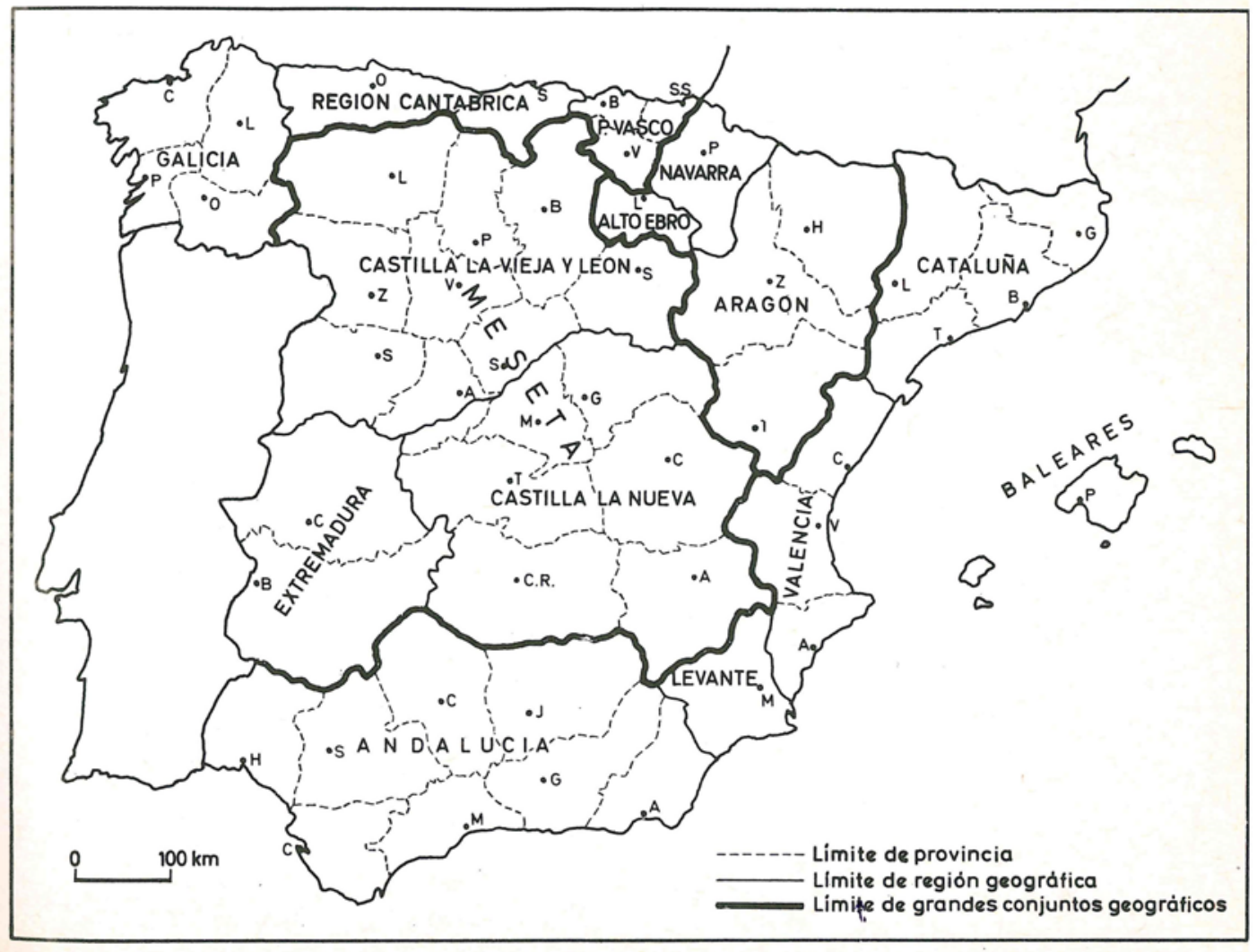

Fuente: GRE (1968, p. 25). Editorial Ariel

Pero Mensua va más allá: se lamenta en las páginas de introducción a esa unidad del valle del Ebro a la que atribuye "una grandiosa simplicidad" en su configuración orográfica, de que no se incorporen en ella las tierras ibéricas leridanas. "La unidad fisiográfica aconsejaría compartir en este aspecto el estudio del valle del Ebro con la vecina región catalana, que asoma ampliamente en el valle en toda la provincia de Lérida, pero que, en atención a otras razones de tipo humano y económico es estudiada en el conjunto catalán" (Mensua en GRE, p. 195). También de forma menos explícita, dice en otro momento que Soria ha quedado en Castilla, aun cuando forma parte de las montañas ibéricas.

El asunto de Lleida tiene interés porque se relaciona con una iniciativa de los años sesenta para que la provincia quedara separada de Cataluña en los manuales escolares y se incorporara al valle del Ebro. En efecto, a mediados de ese decenio, se había planteado por parte del Consejo Económico y Síndical "I'absurd propòsit d'encorporar en els llibres escolars les terres de Lleida, en la 'regió' geográfica dita 'Depresión del Ebro'", según lo cuenta Solé. La propuesta había abierto heridas en Cataluña, y se había organizado en su contra una campaña en la que participó vigorosamente la Societat Catalana de Geografia. Se organizaron ciclos de conferencias a cargo de economistas, políticos, intelectuales y geógrafos (entre ellos Solé, Casas y Deffontaines) que dieron como resultado el libro Les terres de Lleida en la geografia, en l'economia y en la cultura catalanes 
(1967). En lo que aquí interesa el incidente acabó reforzando la amistad de Solé y Terán. En efecto se había pedido un dictamen a la Real Sociedad Geográfica y a la Universidad de Madrid en apoyo de la permanencia en Cataluña: mientras la primera se mostraba reticente, ${ }^{16}$ la cátedra universitaria encabezado por Terán se adhirió a la declaración de la SCG y afirmó que lo más frecuente es que "las regiones naturales y humanas no coincidan", que la región geográfica es la humana, es decir el trozo del espacio "cuya individuación fisonómica resulta de su organización y conformación por un grupo de hombres en cuyas manos ha sido la materia prima que ellos han modelado de acuerdo con su privativo sistema de ideas y fines." Es una frase de un artículo de Terán que se incorporaba al dictamen (Terán, 1960, p. 51). De modo que Lleida debía quedar a todos los efectos en Catalunya. ${ }^{17}$

El otro asunto que importa traer a colación es la discrepancia de Jesús García Fernández, discípulo de Terán y catedrático de Valladolid, con el criterio retenido de regiones históricas. Él mismo se encargó de contar muchos años después que en la reunión preparatoria de la GRE, había manifestado este desacuerdo y se había pronunciado a favor de una verdadera división geográfica o ecológica, más cercana de la de Lautensach, aunque sin compartír los criterios de este (García Fernández, 2000). Según él, los editores y Solé habrían contrarrestado de inmediato esta idea con la afirmación terminante de que en un libro de geografía regional de España hecho por una editorial catalana, no podía pensarse en que no estuviera Cataluña como tal, en su entidad tradicional. La versión del desacuerdo es confirmada en un intercambio de cartas entre Solé y Jesús García de octubre 1967. El primero le había reprochado al segundo que apenas hubiera desarrollado la parte comarcal de su texto sobre Castilla la Vieja, tal como se habia pedido. Le replica García Fernández que él está en contra del "comarquismo, que es uno de los males que aquejan a la geografía española, además de ser antipedagógico". Y añade: "Creo sinceramente que ha sido un mal criterio elegir las divisiones históricas, que no regiones [...] Me da la impresión, y recuerdo una conversación que tuvimos en Barcelona, que usted en esto se ha dejado llevar un poco por el caso de Cataluña, en donde efectivamente no hay quizá un mejor ejemplo de cómo un pasado histórico que a mi modo de ver es una verdadera civilización, ha hecho que dentro de sus límites tradicionales surgiese una verdadera entidad geográfica." (19.9.1967, subrayado mío). La idea del geógrafo castellano es pues que una cosa es Cataluña, verdadera región histórica, y por lo mismo, región geográfica, y otra que el criterio se pueda trasladar a todas los demás casos. Lo que no aclara García Fernández es cuál era su propuesta alternativa.

16 Según parece a través de las notas y cartas de Solé, Terán fue por primera vez en su vida a la Real Sociedad Geográfica para participar en esta discusión y expresar su idea de que Lérida debía quedar en Cataluña.

17 Todo ello se encuentra de forma detallada en un documento mecanografiado del doctor Solé del 1.8.1985 perteneciente al Museu Geològic del Seminari, Arxiu bistòric i biogràfic. 
La GRE tuvo un gran éxito de ventas, se reeditó en varias ocasiones; la cuestión de Navarra no pasó desapercibida y desencajaba, de forma que, cuando se plantea la revisión completa para una nueva edición a finales de los setenta, Solé Sabarís toma la determinación compartida por casi todos de que Navarra sea tratada por separado, y el capítulo se encarga entonces a Alfredo Floristán, también discípulo de Casas, catedrático primero de Zaragoza y que estaba ya en la universidad privada del Opus Dei de Pamplona, y autor de numerosas obras sobre la agricultura navarra y sus comarcas.

El criterio geográfico de delimitación cambia con la escala, y en unidades más sencillas como son las comarcas ya es perceptible una mayor homogeneidad de paisajes y de formas de vida. (GRE, p. 21) Ahí es donde reside la mayor capacidad del geógrafo regional, las escalas comarcales serían las más aptas para el método regional porque participan ya en ellas la percepción y el arraigo populares. "La Alcarria, Tierra de Campos, Las Hurdes, Ampurdán, Campo de Tarragona, Canal de Berdún, el Baztán, la Plana de Castellón, Huerta de Valencia, Hoya de Baza, etc. son nombres populares correspondientes a otras tantas unidades de rasgos muy definidos." (GRE, p. 21). Para una geógrafa de mi generación, cada uno de estos nombres y de otros, va asociado al del nombre del geógrafo que lo estudió en su tesina o en su tesis, y todas ellas en su conjunto constituyen quizá uno de los mayores capitales de la geografía regional. Cuando se elaboró el Atlas de los paisajes españoles, en los años del cambio del siglo y del milenio, Rafael Mata, uno de los codirectores, se complacía en constatar cómo el trabajo académico y cultural de muchos geógrafos había contribuido a la conservación de esos nombres, y a la identidad de los territorios mencionados.

\section{La codificación del método regional}

\subsection{Geografía general de la región y aspectos regionales}

Una vez fijado el marco regional, los textos de cada región debían contener necesariamente una parte general y otra subregional o comarcal, que lleva el aséptico título de "Aspectos regionales". En la Tabla 1 he intentado recoger algunos datos objetivos, como el número de páginas de cada parte y la proporción respectiva de las partes generales y regionales así, como, con carácter tentativo, algunas ideas que resumen la caracterización, descripción, permanencias y cambios, y criterios de organización del estudio regional en cada caso. Las diferencias son notables y ahora me refiero a ello. 
Tabla 1. Características regiones

\begin{tabular}{|c|c|c|c|c|c|c|c|}
\hline REGIÓN/AUTOR & ÁMBITO & $\begin{array}{l}\text { PÁGINAS } \\
\text { gen/reg } \\
\%\end{array}$ & CARACTERÍSTICAS & $\begin{array}{l}\text { POBLAMIENTO } \\
\text { RECURSOS } \\
\text { ACTIVIDADES } \\
\end{array}$ & PAISAJES & $\begin{array}{l}\text { ELEMENTOS } \\
\text { DE CAMBIO }\end{array}$ & $\begin{array}{c}\text { CRITERIO } \\
\text { DISTRIBUCIÓN } \\
\text { COMARCAL }\end{array}$ \\
\hline $\begin{array}{c}\text { Galicia } \\
\text { M. de Terán }\end{array}$ & $\begin{array}{l}\text { Cuatro } \\
\text { provinvias } \\
\text { gallegas }\end{array}$ & $\begin{array}{c}29 \\
17 / 12 \\
59-21 \%\end{array}$ & $\begin{array}{c}\text { Macizo antiguo } \\
\text { Posición marginal } \\
\text { Aislamiento } \\
\text { Clima atlántico } \\
\text { Rías }\end{array}$ & $\begin{array}{c}\text { Dispersión población } \\
\text { Agroganadería } \\
\text { Minifundio } \\
\text { Policultivo Pesca }\end{array}$ & $\begin{array}{l}\text { Pradera } \\
\text { Cercados } \\
\text { Pazos Hórreos } \\
\text { Camino de } \\
\text { Santiago }\end{array}$ & $\begin{array}{l}\text { Emigración } \\
\text { tradicional y } \\
\text { nueva }\end{array}$ & Litoral/interior \\
\hline $\begin{array}{l}\text { Cantabria } \\
\text { M. de Terán }\end{array}$ & $\begin{array}{l}\text { Asturias } \\
\text { Cantabria }\end{array}$ & $\begin{array}{c}18 \\
7 / 11 \\
39-41 \%\end{array}$ & $\begin{array}{c}\text { Eje montañoso Divisoria } \\
\text { Duero } \\
\text { Contrastes N-S litoral- } \\
\text { interior }\end{array}$ & $\begin{array}{l}\text { Concentración litoral. } \\
\text { Ganado Minería } \\
\text { industrialización }\end{array}$ & $\begin{array}{c}\text { Rasa cantábrica } \\
\text { Hoces gargantas } \\
\text { Praderas } \\
\text { Valle de Pas }\end{array}$ & $\begin{array}{l}\text { Migración } \\
\text { intrarregonal de } \\
\text { montaña a litoral }\end{array}$ & $\begin{array}{l}\text { Litoral/montaña } \\
\text { asturiana- } \\
\text { santanderina }\end{array}$ \\
\hline $\begin{array}{l}\text { País Vasco } \\
\text { M. de Terán }\end{array}$ & $\begin{array}{l}3 \text { provincias } \\
\text { vascas } \\
\text { Imprecisión } \\
\text { contornos }\end{array}$ & $\begin{array}{c}18 \\
10 / 8 \\
55-35 \%\end{array}$ & $\begin{array}{c}\text { Unidad política étnica } \\
\text { lengua } \\
\text { Escasa penetración } \\
\text { histórica }\end{array}$ & $\begin{array}{c}\text { Alta densidad } \\
\text { Industrialización } \\
\text { metalúrgica }\end{array}$ & $\begin{array}{c}\text { Caserío } \\
\text { Explotación } \\
\text { familiar y vivienda }\end{array}$ & $\begin{array}{c}\text { Crisis caserío } \\
\text { y modo de vida } \\
\text { tradicional }\end{array}$ & $\begin{array}{c}\text { Sector } \\
\text { vizcaino/guipuzc } \\
\text { oano/ } \\
\text { alavés }\end{array}$ \\
\hline $\begin{array}{l}\text { Castilla-León } \\
\text { J. García- } \\
\text { Fernández }\end{array}$ & $\begin{array}{l}\text { Castilla La } \\
\text { Vieja y } \\
\text { León }\end{array}$ & $\begin{array}{c}51 \\
47 / 4 \\
82-28 \%\end{array}$ & $\begin{array}{l}\text { Cuenca sedimentaria } \\
\text { Altitud } \\
\text { Aislamiento por } \\
\text { encuadramiento } \\
\text { montañoso } \\
\text { Continentalidad }\end{array}$ & $\begin{array}{c}\text { Sistemas de cultivo } \\
\text { Cerealistas } \\
\text { Escasa productividad } \\
\text { por clima }\end{array}$ & $\begin{array}{c}\text { Campos abiertos } \\
\text { campos cerrados } \\
\text { Monte hueco } \\
\text { Ciudades } \\
\text { medievales }\end{array}$ & $\begin{array}{l}\text { Atraso. Escasa } \\
\text { urbanización } \\
\text { Nuevos regadíos } \\
\text { y cultivos } \\
\text { Emigración }\end{array}$ & $\begin{array}{l}\text { Penillanuras } \\
\text { Campiñas y } \\
\text { Páramos } \\
\text { (calcáreos y de } \\
\text { raña) }\end{array}$ \\
\hline $\begin{array}{l}\text { Castilla la Nueva } \\
\text { y Extremadura } \\
\text { M. de Terán }\end{array}$ & $\begin{array}{l}\text { Castilla la } \\
\text { Nueva } \\
\text { Extremadura }\end{array}$ & $\begin{array}{c}38 \\
16 / 21 \\
42-58 \%\end{array}$ & $\begin{array}{l}\text { Basculamiento W Doble } \\
\text { cuenca Paleozoico/sedim } \\
\text { Abierta por el Oeste } \\
\text { Decadencia meseta }\end{array}$ & $\begin{array}{c}\text { Gran propiedad } \\
\text { arrendamiento } \\
\text { aparcería } \\
\text { Viñedos Manchegos }\end{array}$ & $\begin{array}{c}\text { Dehesa } \\
\text { extremeña } \\
\text { Grandes pueblos } \\
\text { manchegos }\end{array}$ & $\begin{array}{c}\text { Atonía } \\
\text { Crecimiento } \\
\text { Madrid } \\
\text { Inmigración } \\
\text { capital }\end{array}$ & $\begin{array}{l}\text { Campiñas y } \\
\text { páramos, } \\
\text { penillanura } \\
\text { extremeña }\end{array}$ \\
\hline $\begin{array}{l}\text { Valle del Ebro } \\
\text { S. Mensua }\end{array}$ & $\begin{array}{l}\text { Aragón } \\
\text { Navarra } \\
\text { Logroño }\end{array}$ & $\begin{array}{c}43 \\
12 / 31 \\
28-72 \% \\
\end{array}$ & $\begin{array}{c}\text { Unidad depresión más } \\
\text { Pirineos y Sistema ibérico } \\
\text { Eje fluvial }\end{array}$ & $\begin{array}{c}\text { Recursos agrícolas } \\
\text { variables pero } \\
\text { aleatorios }\end{array}$ & $\begin{array}{c}\text { Huertas } \\
\text { tradicionales y } \\
\text { nuevos regadíos }\end{array}$ & $\begin{array}{l}\text { Emigración } \\
\text { Hidroelectrici- } \\
\text { dad } \\
\end{array}$ & $\begin{array}{c}\text { Pirineo, } \\
\text { Depresión central } \\
\text { y sistema ibérico } \\
\end{array}$ \\
\hline $\begin{array}{l}\text { Cataluña } \\
\text { S. Llobet }\end{array}$ & $\begin{array}{c}4 \text { provincias } \\
\text { catalanas }\end{array}$ & $\begin{array}{c}53 \\
18 / 35 \\
34-66 \%\end{array}$ & $\begin{array}{c}\text { Unidad histórica y } \\
\text { lingüística } \\
\text { Colectividad Solidaria } \\
\text { Contrastes morfológicos } \\
\text { climáticos }\end{array}$ & $\begin{array}{c}\text { Dispersión / } \\
\text { Concentración según } \\
\text { clima } \\
\text { Policultivo }\end{array}$ & $\begin{array}{c}\text { Agricultura } \\
\text { intensiva medit. } \\
\text { Morfología } \\
\text { Montserrat }\end{array}$ & $\begin{array}{l}\text { Industrialización } \\
\text { Inmigración } \\
\text { Barcelona síntesis, } \\
\text { cerebro y motor }\end{array}$ & $\begin{array}{c}\text { Montaña } \\
\text { pirenaica, } \\
\text { depresión central } \\
\text { y franja litoral }\end{array}$ \\
\hline
\end{tabular}


Tabla 1. Continuación

\begin{tabular}{|c|c|c|c|c|c|c|c|}
\hline REGIÓN/AUTOR & ÁMBITO & $\begin{array}{l}\text { PÁGINAS } \\
\text { gen/reg } \\
\%\end{array}$ & CARACTERÍSTICAS & $\begin{array}{l}\text { POBLAMIENTO } \\
\text { RECURSOS } \\
\text { ACTIVIDADES }\end{array}$ & PAISAJES & $\begin{array}{l}\text { ELEMENTOS } \\
\text { DE CAMBIO }\end{array}$ & $\begin{array}{l}\text { CRITERIO } \\
\text { DISTRIBUCIÓN } \\
\text { COMARCAL }\end{array}$ \\
\hline $\begin{array}{l}\text { Islas Baleares } \\
\text { B. Barceló }\end{array}$ & $\begin{array}{c}\text { Mallorca } \\
\text { Menorca Ibiza }\end{array}$ & $\begin{array}{c}30 \\
24 / 6 \\
80-20 \%\end{array}$ & $\begin{array}{c}\text { Insularidad mayor que } \\
\text { resto Mediterráneo } \\
\text { Encrucijada pueblos } \\
\text { Estirpe catalana }\end{array}$ & $\begin{array}{c}\text { Importancia histórica } \\
\text { comunicaciones }\end{array}$ & $\begin{array}{l}\text { Agricultura y } \\
\text { comercio en } \\
\text { función } \\
\text { comunicaciones }\end{array}$ & $\begin{array}{l}\text { Turismo como } \\
\text { factor decisivo } \\
\text { Mayor relación } \\
\text { Mallorca-lbiza }\end{array}$ & $\begin{array}{l}\text { Grandes islas } \\
\text { y pequeñas }\end{array}$ \\
\hline $\begin{array}{c}\text { Región } \\
\text { Valenciana } \\
\text { A. López Gómez }\end{array}$ & $\begin{array}{l}\text { Castellón } \\
\text { Valencia } \\
\text { Alicante }\end{array}$ & $\begin{array}{c}45 \\
23 / 22 \\
51-49 \%\end{array}$ & $\begin{array}{l}\text { Oposición llanuras } \\
\text { montañas Variedad } \\
\text { climática Gotas frías } \\
\text { Sucesión culturas } \\
\text { Nuevas poblaciones }\end{array}$ & $\begin{array}{l}\text { Agricultura. Huertas } \\
\text { Cambios cultivo } \\
\text { Vivienda dispersa } \\
\text { Manejo colectivo agua }\end{array}$ & $\begin{array}{l}\text { Huertas } \\
\text { Barracas } \\
\text { Naranjales }\end{array}$ & $\begin{array}{c}\text { Exportación frutas } \\
\text { y verduras }\end{array}$ & $\begin{array}{c}\text { Norte-Centro-Sur } \\
\text { y luego llanura } \\
\text { montañas en } \\
\text { cada }\end{array}$ \\
\hline $\begin{array}{l}\text { Murcia } \\
\text { J. Vilá Valentí }\end{array}$ & $\begin{array}{l}\text { Murcia y } \\
\text { altiplano a } \\
\text { Albacete }\end{array}$ & $\begin{array}{c}20 \\
9 / 11 \\
45-55 \%\end{array}$ & $\begin{array}{l}\text { Prolongación dominios } \\
\text { béticos. Región abierta. } \\
\text { Contraste entre fachada } \\
\text { costera y altiplano } \\
\text { Albacete }\end{array}$ & $\begin{array}{c}\text { Hidrología } \\
\text { espasmódica manejo } \\
\text { aguas } \\
\text { avenidas }\end{array}$ & Huertas & $\begin{array}{l}\text { Expansión cultivo } \\
\text { áridos y } \\
\text { exportación } \\
\text { Espera trasvase } \\
\text { Refinería }\end{array}$ & $\begin{array}{l}\text { Litoral-depresión } \\
\text { prelitoral y tierras } \\
\text { interiores }\end{array}$ \\
\hline $\begin{array}{l}\text { Andalucía } \\
\text { J. Bosque }\end{array}$ & $\begin{array}{l}8 \text { provincias } \\
\text { occid. orient }\end{array}$ & $\begin{array}{c}57 \\
24 / 33 \\
42-58 \%\end{array}$ & $\begin{array}{c}\text { Subdesarrollo Influencia } \\
\text { mirada viajero. } \\
\text { Antigüedad culturas. } \\
\text { Influencia comercio } \\
\text { americano }\end{array}$ & $\begin{array}{l}\text { La agricultura bética y } \\
\text { la de las montañas }\end{array}$ & $\begin{array}{c}\text { Campiña bética } \\
\text { Agricultura } \\
\text { latifundista } \\
\text { Cortijos }\end{array}$ & $\begin{array}{l}\text { Emigración a } \\
\text { Europa } \\
\text { Diferencias } \\
\text { sociales }\end{array}$ & $\begin{array}{l}\text { Baja y alta } \\
\text { Andalucía }\end{array}$ \\
\hline $\begin{array}{l}\text { Islas Canarias } \\
\text { M. de Terán }\end{array}$ & $\begin{array}{l}\text { Tenerife y Las } \\
\text { Palmas }\end{array}$ & $\begin{array}{c}15 \\
7 / 8 \\
47-53 \%\end{array}$ & $\begin{array}{c}\text { Modos de vida hispanos } \\
\text { Formas y fenómenos } \\
\text { volcánicos } \\
\text { Régimen alisios }\end{array}$ & $\begin{array}{c}\text { Ciclos económicos: } \\
\text { Caña, viticultura y } \\
\text { cochinilla }\end{array}$ & $\begin{array}{l}\text { Vegetación } \\
\text { escalonada }\end{array}$ & $\begin{array}{l}\text { Intensificación } \\
\text { agrícola }\end{array}$ & $\begin{array}{c}\text { Islas orientales, } \\
\text { centrales y } \\
\text { occidentales } \\
\text { Disimetrías } \\
\text { barlovento } \\
\text { sotavento }\end{array}$ \\
\hline
\end{tabular}

Fuente: elaboración propia a partir de GRE (1968) 
Vayan por delante algunas cosas sobre la elaboración del libro. La GRE tardó casi diez años en llevarse a cabo. El primer problema fueron los plazos, y las respuestas que dieron los autores a los mismos: a tenor de la insistencia en las cartas de Solé y de Alexandre Argullós, el responsable de la editorial, algunos autores debieron demorarse mucho, entre ellos el propio Manuel de Terán y Jesús García Fernández. En diciembre de 1964, Solé ya les reclamaba el texto con una divertida exclamación: "Han terminado su texto, ilustración inclusive, todos los colaboradores del segundo tomo [el regional] del Manual de Geografía de España, excepto tú [se dirige a Terán] y Jesús. O sea, que jfalta la 'Meseta'!" (16.12.1964). Dos años después consta que aún no estaban enteramente terminados.

Las pautas marcadas eran que en la parte general de la región se dedicara un tercio a la geografía física y dos tercios a la humana, con una distribución característica de los trabajos regionales: medio físico, estudiando sucesivamente relieve, clima, vegetación e hidrología; geografía humana que incluye poblamiento y población, actividades económicas, ciudades. Dicho así, remite directamente a la conocida crítica que se hizo, a partir de las segunda mitad del siglo, a la geografía regional sobre que procedía por compartimentos estancos, "le plan à tiroirs"; pero bien sabemos todos a estas alturas que no siempre eso era enteramente cierto, que a veces se consigue identificar trabazones entre unos y otros hechos quizá no causales pero sí presentes. Al final volveré sobre ello.

La otra instrucción inicial era la de que hubiera proporción entre la parte general y la regional. En la Tabla 1, puede verse que no se logró. Los textos de la Submeseta Norte y de islas las Baleares están claramente volcados hacia la geografía general, en el caso de Barceló probablemente por falta de tiempo o por algún otro motivo. Pero en el caso de la región castellano-leonesa es algo muy expresamente buscado por el autor, cuyas reticencias hacia el "comarquismo" ya he comentado. Advertido por el director de esa desproporción, García Fernández replica que sobran los datos comarcales en una geografía que no quiere ser descriptiva y que están compensados por "una serie de ideas generales que [...] dan idea de la región". Lo contrario, añade el catedrático de Valladolid, sería hacer "una geografía más descriptiva que regional, de lo cual ya tenemos bastantes muestras en los últimos tomos de Montaner y Simón publicados recientemente", crítica tajante al modo de trabajar de los demás. Lo único que consiguió Solé Sabarís es que el autor castellano incluyera algo sobre Soria y sobre la vertiente meridional de la Cordillera Cantábrica, de lo que había prescindido inicialmente en su obsesión de buscar el argumento en la "horizontalidad castellana", manifestada en penillanura, campiña y páramos.

Por el contrario, la presentación de la región de Aragón y Navarra cae en la posición absolutamente contraria, casi tres veces más páginas de aspectos regionales que de interpretación general física y humana. Lo mismo pasa, con menor desproporción, en la Cataluña de Llobet. 
Quiza la razón resida en las tradiciones de los propios territorios, en su complejidad, o en las querencias "más comarquistas" de los autores por utilizar el adjetivo del geógrafo de Valladolid. Pero, sea como fuere, al menos en el Valle del Ebro, las cuestiones de geografía general se quedan, sin duda, cortas.

\subsection{Los factores de identidad}

Lo primero que se puede constatar es que para los territorios que luego se iban a constituir en Comunidad Autónoma de acuerdo con la Disposición Transitoria primera de la CE78, es decir para los que hubieran tenido régimen provisional de autonomía, en dos de los casos, Euskadi y Cataluña, cualquiera que sea la coherencia regional de carácter fisiográfico que se argumente, los autores, Terán y Llobet respectivamente, optan por subrayar desde el principio su unidad de carácter histórico, político y lingüístico. Llobet es particularmente expresivo: "Así, más que a las circunstancias físicas, la unidad catalana se debe al factor humano, a la vida en común a lo largo de muchos siglos, a una lengua propia, a unos caminos que siguiendo los valles que descienden del Pirineo han contribuido a originar un conjunto geográfico unificado y solidario, constituido por una serie de unidades heterogéneas que a primera vista podrían parecer inconexas." (Llobet en GRE, p. 241).

Por el contrario, en el caso de Galicia, Terán, pese que llama a su primer epígrafe "Personalidad de la región gallega", la caracteriza de hecho por su posición marginal y por su carácter de macizo antiguo, constituido de rocas arcaicas y paleozoicas en las que el granito juega un papel predominante y en el que el relieve, pese a la altitud media menor de 500 metros, da lugar a un país de montañas, lomas, cúpulas, superficies de suave ondulación, y poca tierra de llana horizontalidad. Las referencias históricas juegan sobre todo respecto de la posición marginal de Galicia, en donde la romanización se habría limitado a una superestructura administrativa, y que luego habría quedado al margen de las invasiones, en particular de la árabe. Solo el camino de Santiago y la influencia cluniacense habrían abierto Galicia al resto de la península y a Europa y explican una gran Edad Media. La mayor o menor penetración de otros pueblos, y en particular, la mayor o menor romanización es una cuestión que siempre le interesa a Terán resaltar y cuya ausencia se cuida de mencionar en el caso del País Vasco.

No tiene sentido entrar ahora en el detalle de esas caracterizaciones iniciales de las regiones peninsulares, que, por cierto, han sido recogidas de forma profusa y de modo muy retórico, en los preámbulos de los estatutos de autonomía y de muchas leyes autonómicas básicas que se refieren al territorio. Lo comentó con cierto sarcasmo Antonio Muñoz Molina en su libro Todo lo que era sólido (2013): una comunidad habla de que es la más grande, otra de que es pequeña pero que tiene todos los contrastes, mar, llanos y montañas, la tercera de que tiene más número de provincias, y otra más de que es la más variada y a la vez uniprovincial, o de que en ella se han 
sucedido más culturas, etc. Me limito ahora a comentarios generales del libro que se pueden completar con la Tabla 1. La unión de Asturias y Santander para formar la región Cantábrica se defiende por el umbral montañoso que forman desde la Cordillera Cantábrica hasta los Pirineos, por su clima atlántico y la presencia de lluvias, también por los contrastes de vertientes contrarrestando todo ello la división geológica, entre el paleozoico asturiano y el mesozoico santanderino.

Por su parte, ya he comentado cómo defiende Mensua esa gran unidad regional del Valle del Ebro incluyendo junto a Aragón a Navarra y la Rioja, en función del carácter de gran colector y articulador del río. Incluso, trascendiendo las intenciones del libro y de sus directores, el autor caracteriza al Valle como "región ístmica" en la geografía peninsular: "ocupa una posición central entre vecinos más ricos y poderosos. De ahí su importancia desde el punto de vista de la vida de relación y de la red de comunicaciones españolas, que deben seguir necesariamente la ruta del Ebro para enlazar entre sí a las regiones periféricas del cuadrante nordeste de la Península, a estas con la Meseta, las montañas levantinas y las regiones industriales vascas." (Mensua en GRE, p. 200).

El razonamiento que hace Terán a propósito de la submeseta sur es interesante porque enuncia, aunque no desarrolla, el basculamiento de la población entre centro y periferia que se produjo en los siglos XVII y XVIII, a favor de las regiones periféricas y a expensas de las castellanas y meseteñas. "El progreso demográfico fue lento en toda la región [la castellano-manchega] y cuando en el siglo XVIII [sic] se produce el desplazamiento del área de densidades mayores desde el centro hacia las regiones periféricas, la Meseta, decaídas sus industrias tradicionales, entre las cuales contaban las de los tejidos [...] no lograron incorporarse a la restauración económica y demográfica, entonces producida..." (Terán en GRE, p. 163). En ese sentido, la submeseta norte, Castilla la Vieja y León, define su unidad sobre todo por ser esa gran cuenca sedimentaria, deprimida entre montañas muy altas, lo que determina su aislamiento y su clima continental, adverso por la dureza de sus inviernos y su aridez estival. A lo que se debe unir, dice Jesús García Fernández, factores históricos como la permanencia de la vida rural (más del 52 \% de la población activa, cuando escribe el texto), su resistencia a la modernización económica, la escasa urbanización y que las ciudades características sigan siendo las capitales de provincia (García, GRE, pp. 100-101).

En las regiones litorales mediterráneas (la valenciana, la murciana, también la andaluza) la característica es la apertura a sucesivas invasiones y penetraciones desde el Mediterráneo, desde el sur, desde Castilla, hasta la llegada de catalanes y aragoneses y la colonización de las Nuevas Poblaciones. Tanto en Valencia como en Murcia, y desde luego en Andalucía se reconoce la muy honda huella de los siglos islámicos, en relación con los regadíos, las ciudades y otras cuestiones, 
y, en cambio, se advierte también la crisis provocada por la expulsión de los moriscos. Finalmente, en estas presentaciones llama la atención que Joaquín Bosque sea el único que opte por una caracterización mucho más social, y no dude en hablar desde los primeros párrafos del subdesarrollo andaluz, que habría sido tergiversado en parte por esa atracción que ejerce Andalucía sobre los viajeros, y que tantos mitos románticos ha alimentado. "Andalucía es una de las unidades regionales mayores de España. [El desequilibrio entre su población y su renta per capita, $67 \%$ de la nacional], explican su característico subdesarrollo. [...] [C]omo dice Sorre, más que cualquier otra parte de la Península ejerce una intensa seducción sobre las imaginacion. [...] Andalucía es una de las Españas exteriores a la Meseta." (Bosque, en GRE, p. 387).

No debo terminar este apartado sin mencionar la consideración bastante escasa prestada en el libro a las islas Canarias. Probablemente el que se ocupara Terán fue porque nadie estaba en condiciones de hacerlo. Todavía no habían ido a las Canarias y permanecido en ellas los profesores de geografía de la nueva generación, el primero de los cuales fue Francisco Quirós Linares, que dejaron un número importante de buenos discípulos. Cuando al final del periodo que estoy revisando, Solé quiere la revisión completa del libro no duda en decirle a Terán que para Canarias piensa en Eduardo Martínez de Pisón. Por cierto, para Asturias obtiene incluso la conformidad de Francisco Quirós, y este le dice que recurra a José Ortega Valcárcel para la parte de Santander, de Cantabria, rompiéndose así la anterior unidad.

No parece posible sistematizar, como se advierte en la última columna de la Tabla, cuáles fueron los criterios de comarcalización en cada caso. Pero, en definitiva, no son muy distintos unos de otros, casi siempre parten de los "contrastes" - palabra que es una de las palabras bisagra o comodín del libro, de las más repetidas- entre unos y otros ámbitos: entre montañas y llanos, entre litoral e interior, entre formaciones geológicas y litológicas distintas. Sería necesario ir a buscar en el detalle del libro los aciertos y los desaciertos, a cartografiar el conjunto de las comarcas.

\subsection{A la búsqueda de ilustraciones y una bibliografía en ejecución}

No me voy a extender mucho sobre la cuestión de las ilustraciones, porque no es fácil asignarlas a sus autores, ya que parece que Solé tuvo a alguien trabajando en las bibliografías y en los materiales gráficos, por si los autores no llegaban a tiempo, y que también la editorial aportó muchos de estos materiales. En todo caso, todo ese material es interesantísimo para situar al libro en su época, y las fotos (en blanco y negro) son muy evocadoras de esos paisajes que ya no son, o que tanto han cambiado. Como en el libro de Montaner, hay bastantes vistas aéreas oblicuas, la enorme mayoría procedentes de la empresa Paisajes Españoles, algunas de T.A.F. El profesor Solé incluye alguna propia, como, por ejemplo, el valle de Arán, la confluencia del Júcar y del Cabriel, y la Hoya de Alcoi. Uno de los ejemplos de las rías gallegas, la de Baquero desde la estaca de Bares procede de la gran colección que sabemos que tenía Hernández Pacheco para su Fisionimía del 
solar hispano, y que parece quedaron en la Universidad. Aparte de estas, las únicas fotos de autor son las que incluye García Fernández: escenas de la trilla en una era en el Esla, calles soportaladas castellanas, casas de pueblo de adobe, etc. Probablemente también sea personal, en el capítulo de Galicia de Terán, la de paisano gallego conduciendo un carro cargado de tojo, para servir de cama al ganado, tirado por cuatro bueyes. Ángel Cabo, de la universidad de Salamanca, me dijo en alguna ocasión que él le hacía las fotos a Terán. Como es habitual en la geografía regional, en general se trata de vistas lejanas o a distancia media, casi sin personas, salvo que sean rurales, como la del aldeano o la de la trilla que tienen un carácter etnográfico.

Sería interesante analizar con cierto detalle los gráficos y los mapas. Para empezar el libro de 1968 incluye en una solapa las distintas hojas de la cartografía topográfica de las distintas regiones a 1:1350 000, indicándose límite de región, además del de provincia. Para las unidades morfoestructurales de una región casi todos los autores usan bloques diagrama y cortes que, con mucha frecuencia, son los de diferentes obras de Solé Sabarís del tomo del relieve de la GEP, o de otros geólogos de su entorno: así ocurre, por ejemplo, con el primero de Galicia, o el del norte al sur de Cataluña (pp. 34 y 245). Era la época de delineación y de los ensayos atentos en semiología gráfica, y se notan diferencias de opción. Hay mapas de distribución mediante puntos, líneas o tramas, círculos distribuidos en triángulos proporcionales, que son de mayor o menor expresividad. Destacan dos gráficos de utilización del suelo por zonas y cultivos del método de Aimé Perpillou (columnas localizadas y tramadas en vertical según el porcentaje de utilización de cada uso del suelo) que se utilizaron bastante en aquellos años por los geógrafos catalanes. Los planos de las grandes ciudades, que son bastantes, tanto de su estructura (de Valladolid y San Sebastián) como los más numerosos de evolución y crecimiento urbanos (La Coruña, Santiago de Compostela, Madrid, Barcelona, Valencia, Cuenca, Zaragoza, Palma, Castellón, Alicante, Murcia, Córdoba, Málaga) sí parecen ser de los respectivos autores. Desde luego Terán estaba estudiando en aquellos años el crecimiento de Madrid y, también, García Fernández publicó un libro sobre la estructura de la capital vallisoletana muy centrado en la propiedad del suelo. La ría de Bilbao, con los contrastes sociales y productivos de ambas orillas es analizada brevemente pero con precisión. No querría dejar de mencionar para terminar la atención que se presta a ciertas edificaciones rurales, con los dibujos con plano, planta y alzado en el caso de la pallaza gallega o el hórreo asturiano -me consta que Terán recurría a su hijo arquitecto para estos dibujos-; las casas manchegas, en cambio están tomadas del etnólogo Jessen y hay varias fotos y descripciones de las barracas valencianas.

Las bibliografías - que no son largas, y a cuya preparación también se debió de contribuir desde Barcelona- muestran esa voluntad de encuentro de conocimientos afines y de cómo se manejaban los autores para el estudio regional entre la geología y la etnografía (Julio Caro Baroja, Luis de Hoyos...), deteniéndose naturalmente en la geografía. Están desde luego las obras de los geólogos 
y geomorfólogos, empezando por los numerosos textos de Solé y de Birot-Solé, que no voy a detallar. También están obras de autores extranjeros que se publicaban traducidos en una sección especial de Estudios Geográficos. Y la vez los libros de autores foráneos que gracias a ser recibidos en las bibliotecas de las diversas sedes del Insituto Elcano, podían ser conocidos y utilizados: citaré como ejemplos el libro de Henri Nonn sobre Les régions côtières de la Galice, 1966, la Galicia de las rías, Les terroirs de la Vieille Castille de Huetz de Lemps (1962) o el Paysage humain de la Costa Brava de Yvette Barbaza (1966). Sirven para poner de manifiesto algo que creo consustancial a la época y es que los modelos de estudio se encontraban en las bibliotecas de geografía, y, por eso y por otras causas, el Elcano fue cantera de geógrafos, investigadores y profesores.

Pero lo más interesante es que se trata de una bibliografía "viva", en el sentido de que están haciéndose los trabajos de investigación, que los autores acaban de trabajar o están trabajando sus zonas, obras algunas de ellas que luego se convirtieron en clásicas que muchos de nosotros, ya que los alumnos de estos maestros las hemos utilizado para la docencia y la investigación. Vaya por delante, para empezar Mallorca. El sur y el sureste de Vicent Rosselló en 1964, alumno de López Gómez, que se ha reeditado este año; y, sin extenderme mucho, citaré algunas que, para mí y mis compañeros, han sido verdaderos clásicos: el texto de Terán, sobre vaqueros y cabañas en los Montes de Pas, o otro sobre Sigüenza; el de García Fernández, sobre los campos abiertos y campos cerrados en Castilla la Vieja, que se publicó en francés, en los Annales E.S.C. en 1964; la tesis de Llobet sobre el Montseny, la tierra y los hombres, que se considera la primera obra de geografía regional hecha en España; los extraordinarios trabajos, hoy más desconocidos, de José Luis Martín Galindo, discípulo y amigo de García Fernández, sobre la dehesa como tipo de explotación agraria, ejemplo de adaptación a la potencialidad biológica de los territorios; también el caserío igualmente como explotación agraria, o el de "Arcaismo y modernidad en Valdeburón (León)"; los de Floristán y Ferrer, sobre la ribera tudelana en Navarra, y el Campo de Cariñena de Manuel Ferrer ; el de López Gómez sobre riegos y cultivos de la Huerta de Castellón; los de Casas Torres, sobre la vivienda en la huerta de Valencia que era su tesis, después sobre las rías de Muros y Noya, o el del valle del Lozoya; finalmente, por no extenderme más, esos primeros trabajos de ciudades medias que son los de Bosque sobre Cartagena y sobre Granada. Todos los que hemos dado clases de geografía regional de España en los últimos decenios del siglo pasado, los hemos utilizado una y otra vez, hemos pedido a los alumnos que los leyeran y comentaran, como ejemplos-tipo, y yo los encuentro citados en aquellas fechas de la GRE con respeto y admiración.

\subsection{Permanencias y cambios. Los cuadros de paisaje}

Los textos de la GRE están escritos en su mayoría a mediados de los años sesenta, cuando el mundo rural empezaba su decadencia, pero todavía seguía estando; unos años después, en los setenta, ya hubieran sido mucho más visibles los enormes cambios en las distribuciones de los 
hechos sobre el territorio y en el paisaje. Por ello me he atrevido a calificar este libro de epocal, está cerrando una época.

Hay algunos cambios que ya empiezan a ser muy evidentes y que recorren el libro con mayor o menor énfasis: el éxodo rural, la urbanización de los grandes núcleos industriales, las grandes obras públicas, en este caso sobre todo, los pantanos, la crisis de las explotaciones tradicionales y la expansión de los regadíos, la aparición del primer turismo, sobre todo en Baleares, y en menor medida, por el tipo de libro que es, la movilización de capital. Los movimientos migratorios no habían entrado en su época de mayor intensidad, porque, como bien sabemos, el abandono de las montañas y del campo empezó en nuestro país bastantes años después que en países como Gran Bretaña, Francia o Alemania, primero por el norte y centro y luego por Andalucía, lo que hizo que esta conservara su potencial demográfico durante más tiempo. También sabemos que estos fenómenos de vaciamiento rural han sido en cambio más intensos y se han prolongado más. En otras palabras en el momento del GRE, todavía había población en el interior peninsular y en las zonas de montaña, y todavía esa población era joven, pero ya estaban ahí los primeros síntomas. En todo caso, las regiones y subregiones se pueden dividir claramente, a medida que avanza la lectura del libro, entre expulsoras de población y receptoras de una inmigración que en estos momentos está muy polarizada en sus llegadas: Madrid, Barcelona, Bilbao, en menor medida Valencia.

Más traducción en el paisaje tienen ya las grandes obras hidráulicas. "La pujanza energética del valle del Ebro" es subrayada por Mensua que constata que "los recursos hidroeléctricos de la red hidrográfica del Ebro, sobre todo en las zonas de cabecera de los afluentes pirenaicos, han sido puestos en explotación desde hace pocos años a un ritmo acelerado" de forma que el valle del Ebro se constituye en importante mercado suministrador, puesto que solo consume el $57 \%$ de su producción. (Mensua en GRE, pp. 206-207). La visión en este sentido es optimista, de un porvenir energético prometedor, ya que siguen sin agotarse los recursos ni del Ebro, ni del Pirineo. Leído hoy, produce vértigo pensar que no había todavía la más mínima reflexión sobre los daños causados a los recursos y a los territorios por las extracciones. Lo mismo pasa con la repoblación forestal, a la que Terán ve todavía en Galicia con un gran margen de posibilidades, aunque advierte la cautela de que no toda la superficie estimada forestal ha de repoblarse, pues una buena parte debe destinarse a pastizal (Terán en GRE, 46). En todo caso, no hay todavía pensamiento ambiental en el libro, más allá de la adecuación de ciertos sistemas de cultivo o tipos de explotación al medio, por ejemplo, las dehesas.

Llegados a este punto, en un libro que trata de interpretar los ajustes matizados y dotados de capacidad de permanencia entre el medio y la acción humana, destacan algunos cuadros de paisaje que es donde la geografía regional y su lenguaje parecen lograr sus mayores éxitos. Leemos en Terán sobre Galicia: " El minifundio, la dispersión parcelaria y el policultivo se inscriben 
en el paisaje gallego en la forma de un mosaico de diminutas piezas de forma diversas, separadas por cercas, setos o linderos y una densa red de caminos con las servidumbres de paso...." (Terán, en GRE, p. 43). O este otro sobre la penillanura extremeña, también de Terán: "Paisaje litológico el extremeño, de austera entonación cromática en armonioso acorde con la vegetación de pardas encinas y matorral leñoso de oscuro verdor. Igualmente austera, pero distinta, la gama en la tierra llana y en las campiñas, de suelos calcáreos que blanquean bajo el rastrojo de los veranos; de margas grises y arcillas rojas, sobre las que destacan las frescas pinceladas verdes de la vegetación de las riberas y el apagado verdor de los olivares" (GRE, p. 172).

Es cierto que Terán era probablemente el que mejor escribía. Pero aunque menos evocadoras, propongo otras imágenes: "Por eso es la zona catalana de paisaje más típicamente mediterránea, de relieve movido, con cultivos de secano variados, presididos por la trilogía clásica del olivo, la vid y los cereales y pequeñas franjas de regadío en donde la tierra se aprovecha al máximo y se da una agricultura intensiva estimulada por la proximidad de las grande aglomeraciones urbanas" (Llobet, en GRE, p. 283). O esta última de López Gómez resumiendo la distribución de los usos en los llanos litorales levantinos: "Al sur se encuentra la Plana de Castellón, cruzada por el Mijares, que da lugar a una extensa huerta, acrecida por numerosos pozos. Cultivo esencial es el naranjo y en segundo lugar las hortalizas; en las zonas pantanosas costeras, arroz y marjales, avenadas con anchas franjas para cultivos hortícolas" (López Gómez, p. 357).

A mediados de los años setenta, Solé todavía trabajó para hacer una nueva geografía regional de España, no ya solo actualizada, sino revisada a fondo, con nuevas perspectivas y nuevos autores entre los que tenía seleccionados al menos, a Floristán para Navarra, Quirós para Asturias y Martínez de Pisón para Canarias. No pudo ser: el libro se reeditó en 1987, puesto al día y actuando de coordinador Vilá Valentí, que figura junto a los dos directores. Al año siguiente, diez años después de la GRE, aparece la Geografía general de España.

\section{Conclusiones: a vueltas con el posibilismo}

Quizá la idea que más quiere transmitir este texto es que merece la pena volver la vista atrás para reencontrar a los que han sido nuestros maestros o nuestros antecesores, porque nos ayudan en el ejercicio de nuestra propia realidad y nuestra práctica. Pero además, tenemos de algún modo deberes para con ellos, somos responsables - utilizando una expresión de Terán en una de sus "Hojas de herbario", titulada 'Nuestros deberes con las cosas'- somos responsables, repito, de que no se apaguen y enmudezcan (Terán, 1984; Gómez Mendoza, 1987, p. 45). Vincent Berdoulay decía recientemente en las sesiones de la Comisión de Historia de la Geografía de la UGl, en su congreso de verano 2018 en Québec, que los geógrafos somos muy dados a tener problemas con nuestra historia, a rebajarla, a banalizarla, a interpretarla por estereotipos, geógrafos coloniales y colonialistas, geógrafos nacionalistas, conservadores, descriptivos, en todo caso una 
disciplina débil, que somos los primeros en considerar así. Se han producido tantos giros epistemológicos en nuestra historia, tantas descalificaciones apresuradas y terminantes, que tendemos a caricaturizar a los autores y las obras del pasado. Mi empeño en esta ocasión ha sido conmemorar un libro que supuso un esfuerzo conjunto bajo la dirección de dos inmensos maestros una presentación de escuela, un manual de calidad y con el tamaño oportuno -que lo hacía transportable sobre los terrenos de estudio-, una obra, sin duda con limitaciones, pero que probablemente es uno de los libros de geografía más leídos y utilizados por geógrafos y no geógrafos.

Fue una presentación de profesores universitarios en los años en que una sociedad y unos territorios, que habían estado detenidos, reprimidos, se abrían al mundo moderno, a Europa, al desarrollo económico, al conocimiento mutuo interregional, pero todavía con usos y explotaciones arcaicos, instituciones antiguas y autoritarias, e infraestructuras muy por debajo de las necesidades. En ese sentido, la Geografía Regional es una obra de época, indispensable para entender las energías acumuladas y las direcciones del cambio pocos años antes del final de la dictadura. Pese a que la organización regional propuesta pudiera parecer -en la medida en que se acomoda a las divisiones históricas y además con una justificación endeble- una opción que renunciaba a la propia autonomía del razonamiento geográfico, es evidente que la historia constitucional y autonómica ha confirmado el acierto: las regiones geográficas no solo eran las humanas sino en gran medida las históricas, necesitadas de ajustes, y sin duda con defectos que no se han corregido. El gran acierto de la Constitución de 1978, que ahora cumple cuarenta años, fue probablemente el principio dispositivo de organización autonómica; quizá también uno de los grandes problemas del desarrollo constitucional haya sido, en cambio, una aplicación homogeneizadora, mediocre y recelosa. Aunque esta cuestión esté muy alejada de lo que aquí he tratado, sí hemos podido ver cómo alguna latencias territoriales se manifestaban ya en el libro de Solé y Terán.

Queda el asunto del posibilismo en el que se reconocían unos geógrafos que elaboraron sus textos a la escala regional y subregional siguiendo el método de la geografía francesa, es decir planteando la relación de los hombres con la naturaleza y la tierra lejos de toda subordinación causal determinista, en un marco de contingencias que permitía reconocer unidades fisionómicas, "mosaico de formas diferenciadas por su forma y color". Terán había escrito sobre ello estableciendo que las claves residen precisamente en los matices, en la dosificación de las elementos, en cómo los hombres se han ido adaptando históricamente al medio en función de su conocimientos, de sus fines, de su capacidad económica, técnica y perceptiva. "Toda adaptación del hombre al medio se hace a partir de un saber de este", dejó escrito el maestro (Terán, 1987 [1966], pp. 105-119), y, por tanto, el sujeto de la relación pasa a ser el hombre, y no el medio. Por ello importan las escalas y los tiempos: solo a escala de los grandes ámbitos territoriales la 
empresa humana y el medio físico se corresponden; pero quizá también es en el otro extremo de la escala, en ámbitos pequeños, donde se puede establecer entre los hechos de orden natural, biológico y social un sistema de correspondencias. Siempre teniendo en cuenta, en todo caso, que en muchos marcos territoriales las influencias del exterior y la circulación de hombres, bienes, técnicas e ideas quiebran el marco de concatenaciones y aconsejan evitar una lectura solo hacia el interior.

Olivier Orain, el autor que tan bien ha teorizado el realismo de la escuela geográfica, habla de forma poco benevolente de lo que llama la "miseria del posibilismo" desde el momento en que prima una versión caricaturesca del tipo "la naturaleza propone, el hombre dispone". Sin duda, en esta obra a veces se recurre demasiadas veces a términos genéricos, conceptos que actúan de comodines, que sirven de subterfugios para demostrar un cosa o la contraria: me refiero por ejemplo a "contrastes" o "complejidad" que, una vez caracterizada una unidad o personalidad regionales, se usan para razonar en sentido contrario, una región tiene personalidad pero, cuidado, también tiene muchos contrastes. También ocurre quizá con "diversidad" y "unidad", que muy a menudo se utilizan juntos, en el sentido de que la diversidad no impide la unidad, y a la inversa. Esta es, sin duda, una de las razones por las que al recurso al posibilismo puede resultar insuficiente.

También es posible encontrar en la GRE formulaciones preocupantes por demasiado simples, en el sentido de aptitudes y réplicas, por ejemplo: "el conjunto de las condiciones naturales suponen aptitudes y posibilidades que el hombre ha sabido aprovechar", como dice en una ocasión, Llobet; en otro lugar, Mensua habla de "la diversidad de aptitudes de un relieve variado que las condiciones de suelo y los matices del clima vendrían a completar". Son enunciados casi de significado nulo. Pero también las hay que introducen matices, y sobre todo que recurren a hechos de organización humana, históricamente datados: "La disposición de las formas de relieve, las aptitudes diversas del suelo para su aprovechamiento agrícola y la diferente organización del terrazgo, dan lugar a esas organizaciones del paisaje que se conocen como comarcas" (GRE, p. 150). También se enriquece el razonamiento cuando los factores del medio mutan en distintos momentos de la historia; García Fernández por ejemplo señala que las condiciones climáticas castellanas - adversas- no habrían tenido el mismo significado en tiempos históricos, en que podía primar algún otro factor como la situación.

Por encima de todo, estamos ante una obra mayor de la geografía regional española, esa forma de conocimiento que apuesta por la combinación de los hechos, para luego ir declinándolos como medios, regiones, comarcas, paisajes. Una geografía que se mueve bien en lo monográfico y en la que se reconocen escrituras individuales, pero en la que los autores que contribuyen comparten formación, valores, lecturas, referentes. Una obra paradigmática por el éxito que tuvo, pero también por cómo se reconocieron en ella los geógrafos de dos generaciones, y por la categoría y 
autoridad de sus directores y autores. Una obra paradigmática por el reconocimiento de sí misma, pero también por la dimensión, categoría y autoridad de sus maestros y directores, también de sus autores.

Agradecimientos: La autora agradece a Jorge Olcina y Pilar Paneque el estímulo y la ayuda que le han dado para escribir este artículo.

Declaración responsable: La autora declara que no existe ningún conflicto de interés en relación a la publicación de este artículo. 


\section{Bibliografía}

Birot, P., \& Solé Sabarís, LI. (1954). Investigaciones sobre la Cordillera Central española. Madrid: Instituto J. S. Elcano.

Casassas, LI. (1981). De la bibliografía de Pau Vila a partir de 1925. Revista de Geografía, 2, 195-204.

Dantín Cereceda, J. (1942) [1922]. Regiones naturales de España. Consejo Superior de Investigaciones Científicas.

Drain, M. (1964). Géographie de la Péninsule Ibérique. Paris: PUF.

García Fernández, J. (2000). La región y los cambios regionales en España. Conferencia leída en 1998 en el Instituto de Geografía de Alicante. Investigaciones Geográficas, 24, 5-15.

García Ramón, M. D., \& Nogué, J. (1992). Práctica y profesionalización de la geografía académica española. In Real Sociedad Geográfica \& Asociación de Geógrafos Españoles, La Geografía en España (1970-1990) (pp. 60-69). Aportación Española al XXVII Congreso de la Unión Geográfica Internacional, Fundación BBVA.

Gómez Mendoza, J. (1997). La formación de la escuela española de geografía: 1940-1952. Ería, 42, 107-142.

Gómez Mendoza, J. (2007). Geografía e historia. Encuentros y desencuentros en Francia y en España a lo largo del siglo XX. In A. Cohen Anselem \& R. Gerardo Peinado, Historia, historiografía y ciencias sociales (pp. 101-148). Granada: Universidad de Granada.

Gómez Mendoza, J., \& Marías, D. (2007). Biografía de Manuel de Terán. In Manuel de Terán, geógrafo (1904-1984) (pp. 2-17). Madrid: Publicaciones de la Residencia de Estudiantes.

Gómez Mendoza, J. (2010). Los otros pensionados: Economía, arquitectura, ingeniería y geografía. In J. García Velasco \& J. M. Sánchez Ron (Coords.), La Junta para Ampliación de Estudios e Investigaciones Científicas en su centenario (pp. 242-333). Madrid: Residencia de Estudiantes.

Gómez Mendoza, J. (2018). A l'ombre du franquisme pendant la Seconde Guerre Mondiale: géographes français et espagnols dans les turbulences politiques et diplomatiques (1936-1950). In M. Claire Robic (Ed.), Géographie et géographes français à l'épreuve de la seconde guerre mondiale. Paris: L'Harmattan (Unpublished).

Gómez Mendoza, J., Lois, R., \& Nel.lo, O. (Eds.) (2013). Repensar el Estado. Crisis económica, conflictos territoriales e identidades políticas en España. Santiago de Compostela: Universidade de Santiago de Compostela. 
Hernández-Pacheco Estudios Geográficos, LXXII, E. (1955-56). Fisiografía del solar hispano. Madrid: Real Academia de Ciencias Exactas, Físicas y Naturales.

Herrero Fabregat, C. (2011). Nuevo concepto de la geografía militar en el primer tercio del siglo XX. Estudios Geográficos, LXXVII(270), 323-335.

Lautensach, H. (1964). Die Iberische Halbinsel [Geografia de España y Portugal]. Munich: Kaiser. López Ontiveros, A. (1992). La enseñanza de la geografía en la universidad española. In RSGAGE, La Geografía en España. Aportación Española al XXVII Congreso de la Unión Geógrafica Internacional (pp. 3-15). Washington: Fundación BBVA.

Marías, D. (2007). La contribución de Manuel de Terán a los estudios geográficos de España y Portugal. In Manuel de Terán, 1908-1984 (pp. 185-209). Sociedad Estatal de Conmemoraciones Culturales, Residencia de Estudiantes.

Martínez de Pisón, E., \& Ortega, N. (Eds.) (2007). Manuel de Terán (1904-1984). Geógrafo. (Catálogo exposición). Sociedad Estatal de Conmemoraciones Culturales, Publicaciones Residencia de Estudiantes.

Montaner y Simón (1930). A nuestros lectores (Hoja voladera). In P. Vidal de la Blache \& L. Gallois, L. (dir.). Geografía Universal, Tomo XVIII. Barcelona: Montaner y Simón.

Muñoz Jiménez, J. (2005). La perspectiva naturalista en el magisterio y en la obra geográfica de Manuel de Terán. Anales de Geografía de la Universidad Complutense, 25, 17-20.

Orain, O. (2009). De plain-pied dans le monde. Ecriture et réalisme dans la géographie française au $X X^{\circ}$ siècle. Paris: L'Harmattan.

Orain, O. (2018). Misère du possibilisme. In Le blog d'Olivier Orain. Retrieved from http://www.esprit-critique.net/article-10489023.html

Ortega Cantero, N. (1997). Juan Dantín Cereceda y la geografía española. Ería, 42, 7-34.

Ortega Cantero, N. (2003). El modelo de la geografía francesa y la modernización de la geografía española. Ería, 61, 149-158.

Ortega Cantero, N. (2006). La Junta para Ampliación de Estudios y la modernización de la geografía española. Boletín de la Institució Libre de Enseñanza, 63-64, 153-174.

Paül, V. (2017). El paisatge en la Geografia de Catalunya de l'editorial Aedos: algunes lectures interpretativse. Treballs de la Societat Catalana de Geografia, 83, 131-171.

Quirós, F. (1997). Un geógrafo del exilio: Leonardo Martín Echeverría (1894-1958). Ería, 42, 67-88. 
Ribeiro, O. (1955). Portugal, tomo V Geografía de España y Portugal. Barcelona: Editorial Montaner y Simón. Retrieved from http://www.orlando-ribeiro.info/bibliografia/1951_1960.htm

Riudor, LI. (1987). La 'Geografía Universal' de Vidal de la Blache y la influencia francesa en la geografía regional española del último siglo. Estudios Geográficos, XLVIII(187), 169-186.

Riudor, L. (1988). La 'Geografia Universal' de Vidal de la Blache en la geografía española del segle XX. Treballs de la Societat Catalana de Geografia, 141-153.

Sáez Pombo, E., Gómez Mendoza, J., Mollá, M., \& Luna, G (2018) [1984]. El campus de la Universidad Autónoma de Madrid. Del tardo franquismo a la democracia. Madrid: UAM.

Solé Sabarís, L. (1975). Sobre el concepte de regio geografica i la seva evolucio y su evolució. In Miscel.lània Pau Vila: biografia, bibliografía, Treballs d'homenatge (pp. 413-476). Editorial Montblanc-Martín.

Solé Sabarís, L. (1982-1983). Sobre el concepto de región geográfica y su evolución. Didáctica Geográfica, 10-11, 3-72.

Solé Sabaris, L. (1984a). Sobre la naixença i el desenvolupament de la moderna geografía. Treballs SCG, 4, 15-35.

Solé Sabarís, L. (1984b). Evocació de don Manuel de Terán, geógrafo, humanista y mentor. Documents d'Anàlisi Geogràfica, 5, 191-203.

Solé Sabarís, L. (1997). Paralelismo de Pau Vila y Manuel de Terán, maestros de la geografía española. In La geografía española y mundial en los años ochenta. Homenaje a D. Manuel de Terán (pp. 87-104). Madrid: Editorial de Universidad Complutense.

Terán, M. de (1952). "La genialidad geográfica de la Península Ibérica", Geografía de España y de Portugal, Barcelona: Montaner y Simón, Vol. I [El relieve de Solé Sabarís] p. 1. 13.

Terán, M. de (1957). La causalidad en Geografía humana. Determinismo, posibilismo y probabilismo. Estudios Geográficos, XVIII, 237-308.

Terán, M. de (1960). La situación actual de la geografía y las posibilidades de su futuro. In Enciclopedia Labor, IV (pp. 39-56). Barcelona.

Terán, M. de (1979). Homenaje a don Luis Solé Sabarís. Estudios geográficos, XL(156-157), $259-261$.

Terán, M. de (1982). Pensamiento geográfico y espacio regional en España. Varia geográfica. (Edited by Joaquín Bosque Maurel). Madrid: Universidad Complutense de Madrid. 
Terán, M. de (1984). Hojas de herbario y otras cosas. In Homenaje a Julián Marías (Coord. by F. Chueca Goitia, E. Lafuente Ferrari, R. Lapesa Melgar \& M. Terán Álvarez) (pp. 681-699). Madrid: Espasa-Calpe.

Terán, M. de, Solé Sabarís, L., et al. (1968). Geografía Regional de España. Barcelona: Ariel.

VV. AA. (1966-1967). Les terres de Lleida en la Geografia, en l'Economie y en la cultura catalanes. Presented at the Cicle de Conferencies, Centre Comarcal Lleidata.

Vilá Valentí, J. (1968). La péninsule ibérique [La península ibérica]. Paris: PUF.

Vila Valentí, J. (1997). Los estudios geográficos acerca del conjunto de España y de la Península Ibérica. In La Geografía en España (1970-1990) (p. 221-228). Aportación Española al XXVII Congreso de la Unión Geográfica Internacional. Fundación BBVA. 